\title{
Very-High-Resolution Airborne Synthetic Aperture Radar Imaging: Signal Processing and Applications
}

\author{
By Andreas Reigber, Senior Member IeEe, Rolf Scheiber, Marc Jäger, \\ Pau Prats-Iraola, Member IEEe, Irena Hajnsek, Senior Member IEEE, \\ Thomas Jagdhuber, Student Member IEEE, \\ Konstantinos P. Papathanassiou, Senior Member IEEE, Matteo Nannini, \\ Esteban Aguilera, Stefan Baumgartner, Student Member IeEe, Ralf Horn, \\ Anton Nottensteiner, and Alberto Moreira, Fellow IEeE
}

ABSTRACT | During the last decade, synthetic aperture radar (SAR) became an indispensable source of information in Earth observation. This has been possible mainly due to the current trend toward higher spatial resolution and novel imaging modes. A major driver for this development has been and still is the airborne SAR technology, which is usually ahead of the capabilities of spaceborne sensors by several years. Today's airborne sensors are capable of delivering high-quality SAR data with decimeter resolution and allow the development of novel approaches in data analysis and information extraction from SAR. In this paper, a review about the abilities and needs of today's very high-resolution airborne SAR sensors is given, based on and summarizing the longtime experience of the German Aerospace Center (DLR) with airborne SAR technology

Manuscript received February 13, 2012; revised May 24, 2012; accepted August 25, 2012.

A. Reigber, R. Scheiber, M. Jäger, P. Prats-Iraola, T. Jagdhuber,

K. P. Papathanassiou, M. Nannini, E. Aguilera, S. Baumgartner, R. Horn,

A. Nottensteiner, and A. Moreira are with the Microwaves and

Radar Institute, German Aerospace Center (DLR), Wessling D-82234, Germany (e-mail: andreas.reigber@dlr.de).

I. Hajnsek is with the Microwaves and Radar Institute, German Aerospace Center (DLR), Wessling D-82234, Germany and also with the Swiss Federal Institute of Technology, Zürich 8092, Switzerland.

Digital Object Identifier: 10.1109/JPROC.2012.2220511 and its applications. A description of the specific requirements of high-resolution airborne data processing is presented, followed by an extensive overview of emerging applications of high-resolution SAR. In many cases, information extraction from high-resolution airborne SAR imagery has achieved a mature level, turning SAR technology more and more into an operational tool. Such abilities, which are today mostly limited to airborne SAR, might become typical in the next generation of spaceborne SAR missions.

KEYWORDS | Applications; high resolution; signal processing; synthetic aperture radar (SAR)

\section{INTRODUCTION}

Today, we are on the edge of a new era of operational synthetic aperture radar (SAR) systems. Recent years have shown a rapid development of advanced SAR technology; new sensors embody several novel features, such as higher resolution, partial and full polarimetry, advanced interferometric setups, and new innovative imaging modes. Experimental and operational airborne sensors have been a major driver of this development, since they are usually ahead of the abilities of spaceborne sensors by several years. 
Particularly, the availability of high-resolution SAR data is currently opening a wide field of new applications. SAR data, due to their inherent speckle effect, appear blurred and noisy when compared to optical remote sensing data of the same level of detail. Only on speckle-free, point-like, or linear targets with strong reflection (typically man-made structures or vehicles) the real resolution capabilities of SAR are fully developed. Therefore, to achieve a similar interpretability as optical data, SAR data of significantly higher resolution are usually needed. Recent SAR sensor systems are capable of resolutions down to few decimeters, resulting in images of excellent quality comparable to modern submeter optical systems. This, together with the all-weather day-and-night imaging capabilities, is turning SAR into an ideal tool, particularly for regular monitoring and mapping applications, where a high reliability of the remotely sensed data is essential.

Radar images contain quite different information than images obtained from optical or infrared sensors. While in the optical range mainly molecular resonances on the object surfaces are responsible for the characteristic object reflectivity, in the microwave region, dielectric and geometrical properties become relevant for the backscattering. Radar images therefore emphasize the relief and morphological structure of the observed terrain as well as changes in the ground conductivity, for example, caused by differences in soil moisture. Because of the sensitivity to dielectric properties, SAR images, in principle, also can provide information about the condition of vegetation, an important fact for agricultural and forestry applications. Another important feature of SAR data results from the propagation characteristics of microwaves. Microwaves are capable of penetrating into vegetation and even the ground up to a certain depth [1]. The penetration capabilities depend on the wavelength as well as on the complex dielectric constants, conductivities, and densities of the observed targets. Shorter wavelengths, like the X-band $(\sim 3 \mathrm{~cm})$, show typically a high attenuation and are mainly backscattered on the surface or on the top of the vegetation. Consequently, at these wavelengths, information about this layer is mainly collected. Longer wavelengths, like L- and P-band ( $\sim 25 \mathrm{~cm}$ and $\sim 100 \mathrm{~cm}$, respectively), normally penetrate deep into vegetation, snow and ice, and often also into the ground. The backscattering then contains contributions from the entire volume.

Additional to conventional, single-channel SAR, two multichannel extensions have gained a lot of attention during the last years: interferometric SAR (InSAR) and polarimetric SAR (PolSAR). In InSAR, two or more SAR images, acquired from slightly displaced tracks and thus under slightly different incidence angles, are combined. Through an analysis of phase differences, these acquisitions allow for the generation of precise large-scale digital surface models. First InSAR experiments were conducted already in the 1970s and the 1980s, using Jet Propulsion Laboratory's (JPL's) airborne and spaceborne sensor [2], [3]. However, it was not until the Shuttle Radar Topography Mission in 2000 [4], which provided medium resolution digital elevation models for most of the land masses on Earth, that InSAR became a highly recognized and operational remote sensing tool. Today, the TanDEM-X mission, consisting of two high-resolution SAR satellites, is generating a new global digital elevation model of the Earth's surface with unprecedented accuracy [5].

Today, InSAR is a powerful and well-established technique, which is operational on most airborne and spaceborne sensors. Besides topographic mapping, an extended version of SAR interferometry, called differential interferometry (DInSAR), can be used for precise mapping of elevation changes [6]. This technique allows the detection of surface deformations on a subwavelength scale, usually in the millimeter range. Due to its extreme precision, DInSAR has found a multitude of applications, ranging from the monitoring of ecological stress-change processes like sudden coseismic displacements or volcanic bulging before eruptions, over monitoring of man-made subsidence due to mining activities [7]-[9] up to measurement of glacier dynamics [9]-[11].

SAR polarimetry (PolSAR) is another major extension of conventional single-channel SAR imaging. Like all electromagnetic waves also microwaves have a vectorial nature, and a complete description of the scattering problem in radar science requires a vectorial matrix formulation. This is the task of radar polarimetry, a technique which was initiated by the introduction of the theoretical concept of the "scattering matrix" by G. W. Sinclair in 1948 [12]. However, it took until the 1980s and the 1990s that highquality polarimetric SAR data became widely available with the growing number of polarimetric airborne sensors like German Aerospace center's (DLR's) E-SAR [13], the Canadian CV580 system [14], or NASA/JPL's AIRSAR [15]. One special characteristic of SAR polarimetry is that it allows a discrimination of different types of scattering mechanisms. This becomes possible because the observed polarimetric signatures depend strongly on the actual scattering process. In comparison to conventional singlechannel SAR, the inclusion of SAR polarimetry consequently leads to a significant improvement in the quality of classification and segmentation results [16]-[18]. Certain polarimetric scattering models [19] even provide a direct physical interpretation of the scattering process, allowing an estimation of physical ground parameters like soil moisture and surface roughness [20], as well as unsupervised classification methods with automatic identification of different scatterer characteristics and target types [21], [22].

Today's new generation of very high-resolution airborne SAR sensors is pushing the limits of what level of information can be extracted from SAR imagery even further. The increased resolution of modern sensors, both spatially and radiometrically, allows the generation of novel information products which has been, to date, not possible with SAR. In many cases, information extraction 
from high-resolution airborne SAR imagery has already achieved a mature level, while in the spaceborne case highresolution applications are still comparatively rare. However, it can be expected that the next generation of spaceborne SAR sensors, to be launched in the coming decade, will bring the novel SAR concepts into regular operation. In the remainder of this paper, a review of the current status of mature information products based on modern high-resolution airborne SAR will be given, together with a description of the current state of the art in high-resolution signal processing for airborne SAR, forming the base for such kind of applications.

This paper is organized as follows. First, in Section II, a brief description of the last generation of civilian highresolution airborne sensors is provided. The following Section III is concerned with the specifics and novel concepts needed for high-quality high-resolution airborne data processing. Section IV gives an extensive overview of various applications based on the availability of highresolution airborne SAR data. Finally, Section V concludes and presents an outlook on upcoming SAR technology.

\section{HIGH-RESOLUTION AIRBORNE SENSORS}

The development of airborne SAR systems for civilian applications started in the 1980s with the AIRSAR system [15] from NASA/JPL and the Canadian CV580 system [14]. In the 1990s, most systems became fully polarimetric, with some of them offering multifrequency operation and resolutions in the meter regime. In the last ten years, several new systems pushed this development further, achieving resolutions in the decimeter regime as well as offering multichannel acquisition capabilities (e.g., SETHI, RAMSES, PISAR-II, F-SAR, and PAMIR). Table 1 gives an overview of several airborne SAR systems showing their basic operation modes. Some of these systems also allow single-pass interferometric capability in higher frequency bands by means of a second antenna mounted on a different position on the fuselage. Alternatively, the SAR antenna and radar front-end can be integrated in pods under the fuselage or under the aircraft wings. Repeat-pass interferometry is also possible in several systems by means of an accurate flight navigation system, which delivers real-time position information of the aircraft to the pilot (or in some cases, directly to the automatic pilot system). By this, the parallel flight tracks can be maintained within a few meters accuracy, allowing the realization of repeat-pass interferometry. Except for the OrbiSAR, IFSAR, and GeoSAR, which are commercially operated, all other airborne systems are designed for research and environmental monitoring purposes.

As one example of a modern high-resolution airborne SAR system, in the following, the F-SAR system will be described in more detail. This new and advanced airborne SAR instrument has been operated by DLR since 2009 as the successor to the former E-SAR system. As the E-SAR, which had been active between 1983 and 2010, also the F-SAR is intended as a technology testbed to establish expertise in SAR system design, signal processing, and image analysis. The F-SAR instrument is constructed mainly from commercial off-the-shelf components and subsystems. Design-critical parts, however, such as the antennas and others, are developed and built inhouse. As the former E-SAR system, F-SAR is installed and operated onboard DLR's Dornier DO228-212 aircraft as the platform of choice.

F-SAR's main design feature is the fully polarimetric operation in five frequency bands, X-, C-, S-, L-, and P-band, with the ability to measure different frequency bands and/or polarizations simultaneously in four recording channels.

Table 1 Overview of Airborne SAR Sensors and Their Main Characteristics. Typical Wavelengths for the Indicated Frequency Bands Are: W-Band: 3 mm, Ka-Band: $1 \mathrm{~cm}$, Ku-Band: $1.7 \mathrm{~cm}$, X-Band: $3 \mathrm{~cm}$, C-Band: $5 \mathrm{~cm}$, S-Band: $10 \mathrm{~cm}$, L-Band: $25 \mathrm{~cm}$, P-Band: $100 \mathrm{~cm}$, and VHF: $500 \mathrm{~cm}$. OrbiSAR, IFSAR, and GeoSAR Are Operated Commercially, Others for Research and Environmental Monitoring Purposes

\begin{tabular}{|c|c|c|c|c|c|c|}
\hline Sensor & Aircraft & $\begin{array}{l}\text { Frequency } \\
\text { Band(s) }\end{array}$ & $\begin{array}{c}\text { Fully } \\
\text { polarimetric }\end{array}$ & $\begin{array}{c}\text { Single-pass } \\
\text { InSAR }\end{array}$ & Institution & Country \\
\hline $\begin{array}{l}\text { AIRSAR [15] } \\
\text { UAVSAR [23] }\end{array}$ & $\begin{array}{c}\text { DC-8 } \\
\text { Gulfstream }\end{array}$ & $\begin{array}{c}\mathrm{P}, \mathrm{L}, \mathrm{C} \\
\mathrm{L}\end{array}$ & $\begin{array}{c}\mathrm{P}, \mathrm{L}, \mathrm{C} \\
\mathrm{L}\end{array}$ & $\begin{array}{l}\mathrm{C} \\
-\end{array}$ & NASA/JPL & USA \\
\hline CV-580 [14] & Convair 580 & C,X & $\mathrm{C}, \mathrm{X}$ & - & CCRS & Canada \\
\hline EMISAR [24] & Gulfstream & $\mathrm{L}, \mathrm{C}$ & $\mathrm{L}, \mathrm{C}$ & $\mathrm{C}$ & TUD & Denmark \\
\hline $\begin{array}{l}\text { E-SAR [13] } \\
\text { F-SAR [25] }\end{array}$ & Dornier 228 & $\begin{array}{c}\text { X,C,L,P } \\
\text { X,C,S,L,P }\end{array}$ & $\begin{array}{c}\text { L,P } \\
\text { X,C,S,L,P }\end{array}$ & $\begin{array}{c}\mathrm{X} \\
\mathrm{X}, \mathrm{S}\end{array}$ & DLR & Germany \\
\hline OrbiSAR [26] & $\begin{array}{l}\text { Embraer } 810 \mathrm{C}, \\
\text { Turbo Commander }\end{array}$ & $\mathrm{X}, \mathrm{P}$ & $\mathrm{P}$ & $\mathrm{X}$ & OrbiSat & Brazil \\
\hline Carabas-II [27] & Sabreliner & VHF & VHF & - & FOI & Sweden \\
\hline SmartSAR [28] & Transall & $\mathrm{X}$ & - & - & Cassidian & Germany \\
\hline GeoSAR [29] & Gulfstream & $\mathrm{X}, \mathrm{P}$ & $\mathrm{X}, \mathrm{P}$ & $\mathrm{X}, \mathrm{P}$ & Fugro & USA \\
\hline $\begin{array}{l}\text { IFSAR [30] } \\
\text { AeS-1/2 [31] }\end{array}$ & $\begin{array}{c}\text { Learjet } \\
\text { Turbo Commander }\end{array}$ & $\begin{array}{c}\mathrm{X} \\
\mathrm{X}, \mathrm{P}\end{array}$ & $\bar{P}$ & $\begin{array}{l}\mathrm{X} \\
\mathrm{X}\end{array}$ & Intermap & USA \\
\hline $\begin{array}{l}\text { PISAR [32] } \\
\text { PISAR-2 [33] }\end{array}$ & Gulfstream & $\begin{array}{l}\mathrm{X}, \mathrm{L} \\
\mathrm{X}\end{array}$ & $\begin{array}{l}\mathrm{X}, \mathrm{L} \\
\mathrm{X}\end{array}$ & $\begin{array}{l}\mathrm{X} \\
\mathrm{X}\end{array}$ & JAXA & Japan \\
\hline PAMIR [34] & Transall & $\mathrm{X}$ & - & $\mathrm{X}$ & FHR & Germany \\
\hline $\begin{array}{l}\text { RAMSES [35] } \\
\text { SETHI [36] }\end{array}$ & $\begin{array}{c}\text { Transall } \\
\text { Falcon } 20\end{array}$ & $\begin{array}{c}\mathrm{W}, \mathrm{Ka}, \mathrm{Ku}, \mathrm{X}, \mathrm{C}, \mathrm{S}, \mathrm{L}, \mathrm{P} \\
\text { X,L,P }\end{array}$ & $\begin{array}{c}\mathrm{Ku}, \mathrm{X}, \mathrm{C}, \mathrm{S}, \mathrm{L}, \mathrm{P} \\
\mathrm{X}, \mathrm{L}, \mathrm{P}\end{array}$ & $\begin{array}{c}\mathrm{Ku}, \mathrm{X} \\
\mathrm{X}\end{array}$ & ONERA & France \\
\hline
\end{tabular}


Table 2 F-SAR Technical Characteristics in the Different Bands: Radio Frequency (RF), Bandwidth (Bw), Maximal Pulse Repetition Frequency (PRF), Transmit Power (PT) and Range/Azimuth Resolution, Sampling, Channels, and Data Rate

\begin{tabular}{|l|ccccc|}
\hline & $\mathrm{X}$ & $\mathrm{C}$ & $\mathrm{S}$ & $\mathrm{L}$ & $\mathrm{P}$ \\
\hline \hline RF [GHz] & 9.6 & 5.3 & 3.25 & 1.325 & $0.35 / 0.435$ \\
Bw [MHz] & 760 & 400 & 300 & 150 & $100 / 50$ \\
PRF [kHz] & 5 & 5 & 5 & 10 & 10 \\
PT [kW] & 2.5 & 2.2 & 2.2 & 0.9 & 0.9 \\
Rg res. [m] & 0.2 & 0.4 & 0.5 & 1.0 & 1.5 \\
Az res. [m] & 0.2 & 0.3 & 0.35 & 0.4 & 1.5 \\
Sampling & \multicolumn{7}{|c}{8 bit real, 1000MHz } \\
Channels & 4 & 2 & 2 & 2 & 2 \\
Data rate & \multicolumn{7}{|c}{ 247 MByte/s max. (per channel) } \\
\hline
\end{tabular}

Furthermore, the system design features two single-pass polarimetric across-track interferometers (XTI) with fixed baselines of approximately $1.6 \mathrm{~m}$ in X-and S-bands. In $\mathrm{X}$-band, there is an additional along-track interferometer with an 89-cm fixed baseline. In all five bands, repeat-pass polarimetric interferometry is a standard mode of operation. Another focus of the design is radar resolution. A resolution of better than $25 \mathrm{~cm}$ in both slant range and azimuth direction can be achieved in X-band by using a stepfrequency approach to yield an effective signal bandwidth of $760 \mathrm{MHz}$. Even at P-band, a resolution of $2 \mathrm{~m}$ is possible. Relevant technical parameters are summarized in Table 2. A view into the aircraft's cabin with the F-SAR hardware mounted is shown in Fig. 1.

While the P-band antenna is mounted underneath the aircraft body, a new antenna hold, carrying the X-, C-, S-, and L-band antennas, is attached to the right side of the aircraft. This construction of the antenna hold prevents

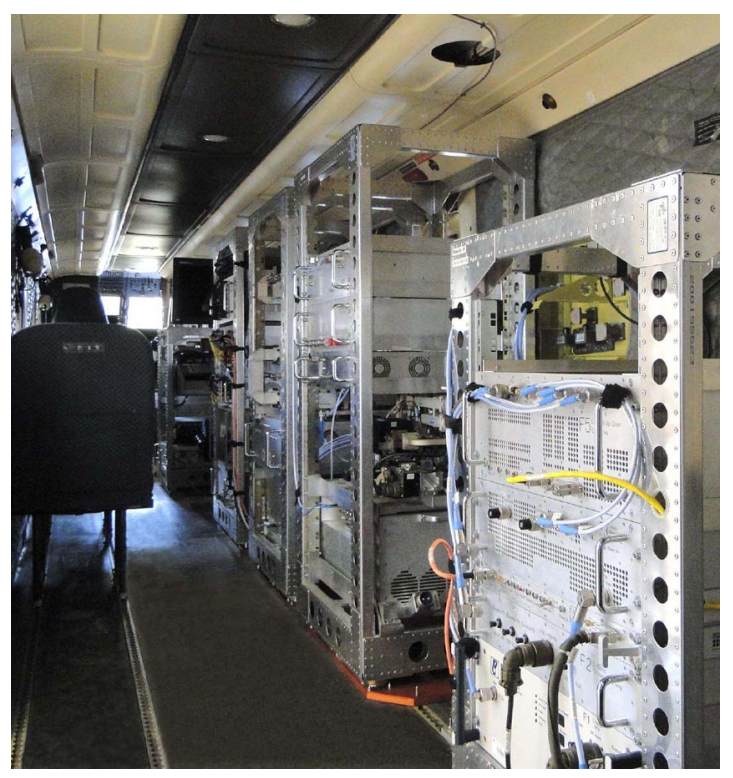

Fig. 1. The F-SAR instrument in the cabin of the Do228 aircraft. Standard instrumentation racks house the radar's electronic units. relative motion between the mount and aircraft frameworks induced by air turbulence and shocks. One aircraft window has been replaced by a feed-through plate to electrically connect the antennas to the radar inside the cabin.

The F-SAR features also a real-time onboard processing unit running on dedicated hardware linked to the data recording units by optical fiber. The onboard processor presently supports simultaneous two-channel quick-look and high-resolution processing, as well as the generation of ground moving target indication (GMTI) products. Additionally, real-time data products can be transmitted to a ground station via a fast microwave downlink.

\section{VERY-HIGH-RESOLUTION SAR SIGNAL PROCESSING}

In parallel to the evolution of airborne SAR sensors toward increased resolution there has been a parallel development of efficient SAR image formation algorithms and motion compensation procedures. These developments were triggered by the relatively high amount of data to be processed with modest computing power and the increasing accuracy requirements with respect to spatial resolution and radiometric and geolocation accuracy. In this section, a brief review of the mostly used image formation algorithms is given, followed by the discussions of recent advancements with respect to motion compensation and radiometric calibration, all being presented as part of an overall airborne SAR processing concept, which is presented first.

\section{A. Airborne SAR Processor Concept}

Spatial resolution as well as radiometric and interferometric calibration accuracy has a direct impact on the ability to measure or infer physical parameters from SAR data. Therefore, it is essential to integrate the best motion compensation and airborne SAR focusing algorithms available into a well-defined and consolidated processing concept to ensure optimum focusing performance (see Fig. 2). New algorithms for motion compensation, antenna pattern correction, and radiometric SAR data calibration are part of it. Due to the increased data rate of multichannel veryhigh-resolution (VHR) systems (e.g., the new F-SAR system records up to $20 \mathrm{~GB} / \mathrm{min}$ corresponding to a factor 120 compared to the former E-SAR system), considerable effort is required for the efficient implementation of timeconsuming processing steps.

The high-resolution data processing of advanced polarimetric and interferometric SAR modes (polarimetry, single- and repeat-pass interferometry, tomographic processing) is considered the core part of each modern VHR SAR processor and must include highly accurate topography adaptive motion compensation. Preprocessing is usually required to roughly compensate for the motion of the aircraft and correct for the nonideal properties of the transmitted pulses. The processing of data acquired in step-frequency mode needs also to be supported in some 


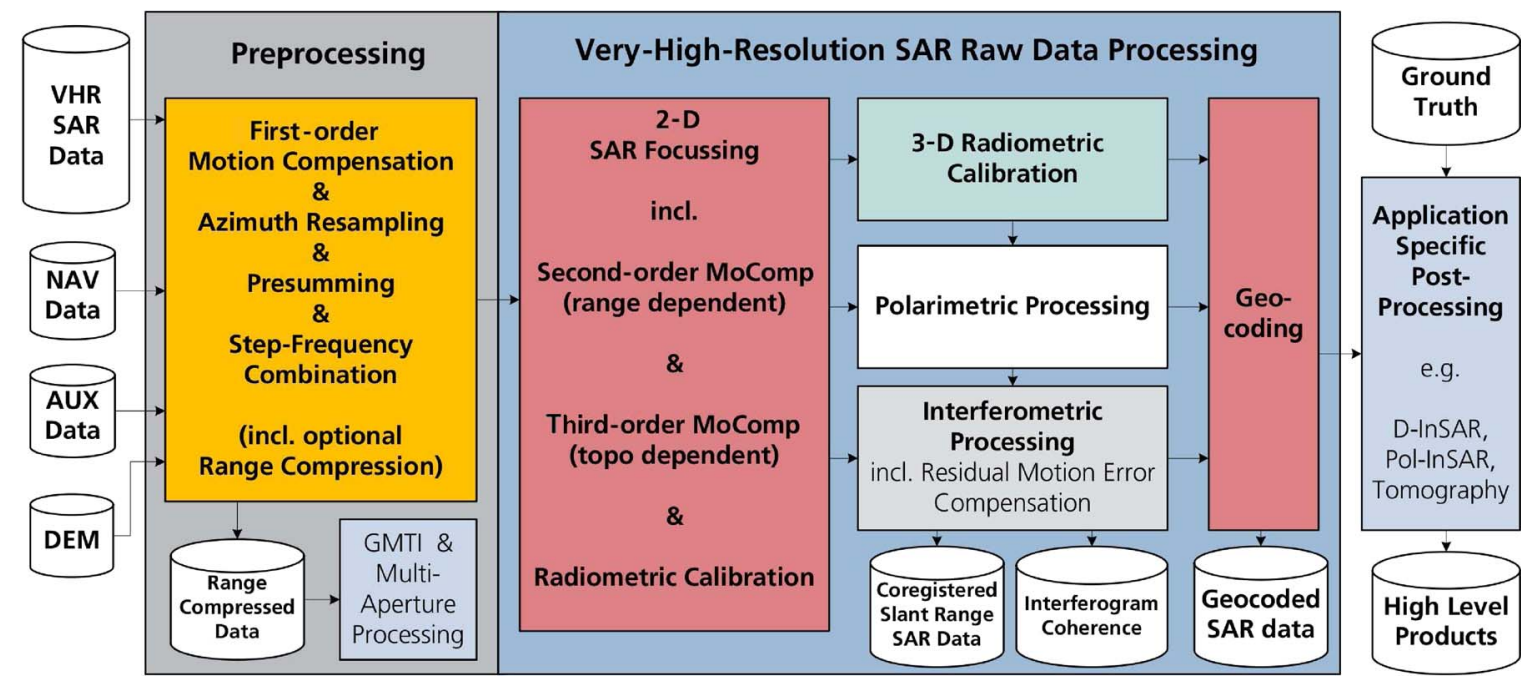

Fig. 2. Required steps for VHR SAR data processing for advanced SAR applications, as implemented for the F-SAR system of DLR.

cases (e.g., VHR X-band data of the F-SAR sensor). For the core 2-D focusing operation, the standard extended chirpscaling (ECS) algorithm is used for F-SAR, but other accurate kernels may be used as well. Highly accurate radiometric and geometric calibration can be ensured by an additional processing step after regular focusing. This additional calibration is based on the full, complex 3-D antenna pattern (in elevation/azimuth/frequency) and computes corrections taking into account the flight track and sensor attitude as well as any variations within the synthetic aperture. As a result, it can improve the radiometric calibration usually performed prior to azimuth compression and, by correcting interchannel phase offsets, also the polarimetric calibration. Georeferencing and resampling to geodetic grids need to be performed for making the data suitable for integration into any geographical information system (GIS). Specific postprocessing algorithms (e.g., Pol-InSAR, tomographic SAR processing, soil moisture retrieval) are conveniently performed on slant range data, and only the resulting final information products are georeferenced.

\section{B. SAR Image Formation Algorithms}

SAR image formation basically consists of a coherent, phase-corrected integration of the recorded raw data samples. The different algorithms deviate from each other in terms of how accurately and efficiently they implement the spatially adaptive summation. In principle, one can distinguish time-domain algorithms, which are most accurate but computationally expensive, and frequency-domain algorithms, which are more effective and generally preferred for operational data processing.

1) Time-Domain Algorithms: Time-domain algorithms, often referred to as direct backprojection (DBP), imple- ment the phase-corrected integration of the raw data echoes for each imaged point separately by taking into account the individual two-way propagation delay. Therefore, they are most accurate and can easily adapt to nonlinear flight geometries or airborne acquisition scenarios with large motion errors. Due to their computational complexity of order $N^{3}$, where $N$ is the number of azimuth and range samples assumed equal, their use is restricted to processing small areas and they serve mainly as reference processors for the development of more efficient algorithms. An efficient implementation of direct backprojection is the fast-factorized backprojection (FFBP) algorithm proposed in [37]. It implements the coherent integration within several steps at different resolution scales, most of them in polar reference systems, thus being able to reduce the computational complexity to $N^{2} \log N$. Initially, it has been proposed as an efficient processor for high-resolution, long-wavelength (VHF) SAR focusing, avoiding the deficiencies of frequency-domain algorithms. In the context of VHR airborne SAR focusing, it serves as a valuable reference also for other frequency bands. Adaptations of the FFBP were made to efficiently focus also bistatic SAR data acquired in combined airborne and spaceborne geometries [38].

2) Frequency-Domain Algorithms: Due to their efficiency, the preferred image formation algorithms work in the frequency domain. A helpful comparison of the different algorithms can be found in [39]. Common to all algorithms is the assumption of a straight rectilinear flight path, without taking into account the motion errors of the aircraft. Among the first algorithms, which were used for airborne SAR processing, was the range Doppler algorithm (RD), which essentially decouples range and azimuth processing at the cost of focusing accuracy. The spatially 
variant range migration correction is performed with interpolations. The most exact algorithm is the wavenumberdomain algorithm, which is known to provide the most accurate focusing performance by implementation of the Stolt mapping in the 2-D frequency domain [40]. Considerable efforts have been made toward the development of algorithms, which avoid the use of extensive interpolations, and the most prominent example is the chirp-scaling algorithm [41]. It has been adapted as the ECS to the airborne scenario by including a two-step motion error correction [42], [43] as well as radiometric corrections of antenna pattern and two-way attenuation, properly taking into account variations of the roll angle. Also for the wavenumber algorithm, adaptations have been proposed for the airborne case, involving a modified Stolt mapping and including motion compensation [44]. However, for efficiency reasons, in most cases, the RD or ECS algorithms are used for the operational processing, but it needs to be stated that the algorithm's focusing accuracy reaches its limits at these VHRs.

\section{Key Motion Compensation Aspects}

Airborne SAR sensors have been and are still used extensively for the development and demonstration of new imaging techniques, often involving several repeated passes over the same area of interest, each being separated by certain spatial baselines. For Pol-InSAR and SAR tomography, predefined spatial baselines, typically separated by some tens of meters, are flown, whereas for change detection and differential SAR applications, the same nominal flight track is preferred. In each track, deviations from a straight flight path occur, which need to be compensated during processing. The RD and ECS algorithms typically implement a two-step motion compensation: a first-order, range-invariant correction at raw data level is performed prior to any presumming or azimuth resampling operation, while the second step is the range adaptive motion compensation, which is conveniently applied after range cell migration correction. Each compensation step needs to correct phase and envelope of the signal according to the line-ofsight difference between the real and nominal tracks.

In high-resolution applications, two problems remain. First, the accuracy of modern navigation systems is typically limited to a few centimeters, leaving a certain amount of uncompensated motion in the data. Second, the accuracy of motion compensation in frequency-domain algorithms is limited in itself because of the narrow azimuth beam assumption, and residual errors might remain in the data, particularly in case of large deviations from the flight track as well as in case of significant topographic variations in the scene. As a result, there are certain challenges imposed by the motion of the aircraft, which has to be considered independent for each overflight and which leads to spatial varying interferometric baselines (see Figs. 3 and 4) and residual motion errors. Any inaccuracy in the measurement and compensation of the platform motion leads

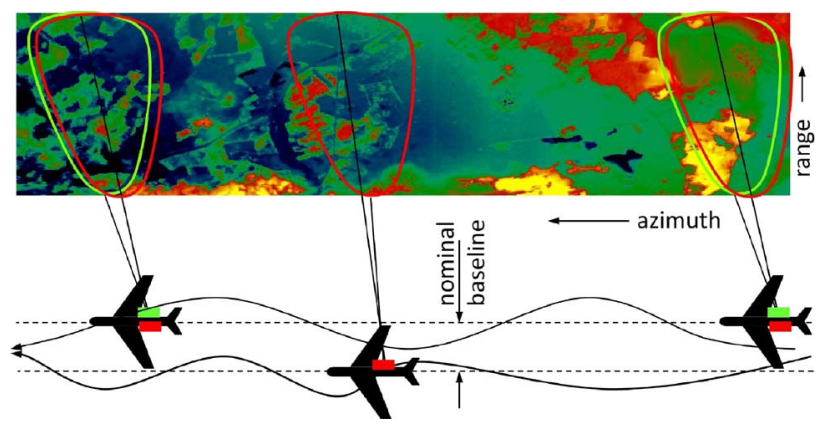

Fig. 3. Acquisition of airborne interferometric SAR data. Single-pass acquisition is possible with two antennas mounted on the same platform and is used for generating digital elevation models (DEMs). Here, the DEM of the Oberpfaffenhofen area is shown over an area of $3 \mathrm{~km} \times 10 \mathrm{~km}$, data being acquired by the E-SAR system of DLR. The repeat-pass baselines, variations being compensated during motion compensation, are used for flexible acquisition of data for differential interferometric, Pol-InSAR, or SAR tomography applications.

to undesired imaging effects—phase errors, defocusing, mislocation-deteriorating especially the interferometric phase and coherence.

During the last decade, several advanced algorithms for improved high-resolution motion compensation have been developed. Such activities were mainly driven by the needs imposed by the Pol-InSAR applications (see Section IV-D), tomographic imaging modes (see Section IV-E), as well as by differential airborne SAR interferometry (see Section IV-C).

1) Topography-Dependent Motion Compensation: During the development and refinement of the airborne repeatpass interferometric processing strategy, it was recognized

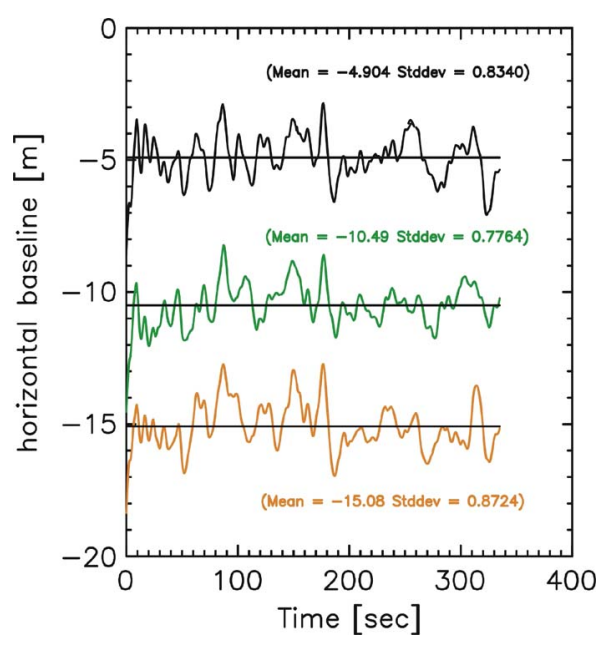

Fig. 4. Real interferometric baselines achieved during INDREX campaign [45]. Deviations are less than $1 \mathrm{~m}$ [root mean square (rms)] for each of the three passes with a nominal horizontal baseline of $5 \mathrm{~m}$. 
that the usual approximations for motion compensation are not sufficient and that topography and residual motion errors need to be taken into account very precisely [46]. Concerning topography accommodation, this led to the parallel development of two algorithms, namely, the socalled precise topography and aperture-dependent motion compensation (PTA) approach [47], and the subaperture topography- and aperture-dependent (SATA) algorithm [48]. A comparison of these algorithms can be found in [49]. They are based on short-time fast Fourier transform (FFT) codes and thus make an effective use of the quasilinear time-frequency correspondence of the SAR azimuth signal. Its application is imperative, not only for processing airborne data in differential SAR interferometric mode, but also for repeat-pass SAR applications in hilly and mountainous areas in general.

The problem at hand is illustrated in Fig. 5, which shows that a different motion compensation is required if the imaged point is not located at the reference height assumed during the traditional two-step motion compensation. Different range/azimuth-dependent phase errors, described by

$$
\Phi_{\text {err }, \text { topo }, i}(r, x)=\frac{4 \pi}{\lambda}\left(\Delta r_{\text {topo }, i}(r, x)-\Delta r_{\text {ref }, i}(r, x)\right)
$$

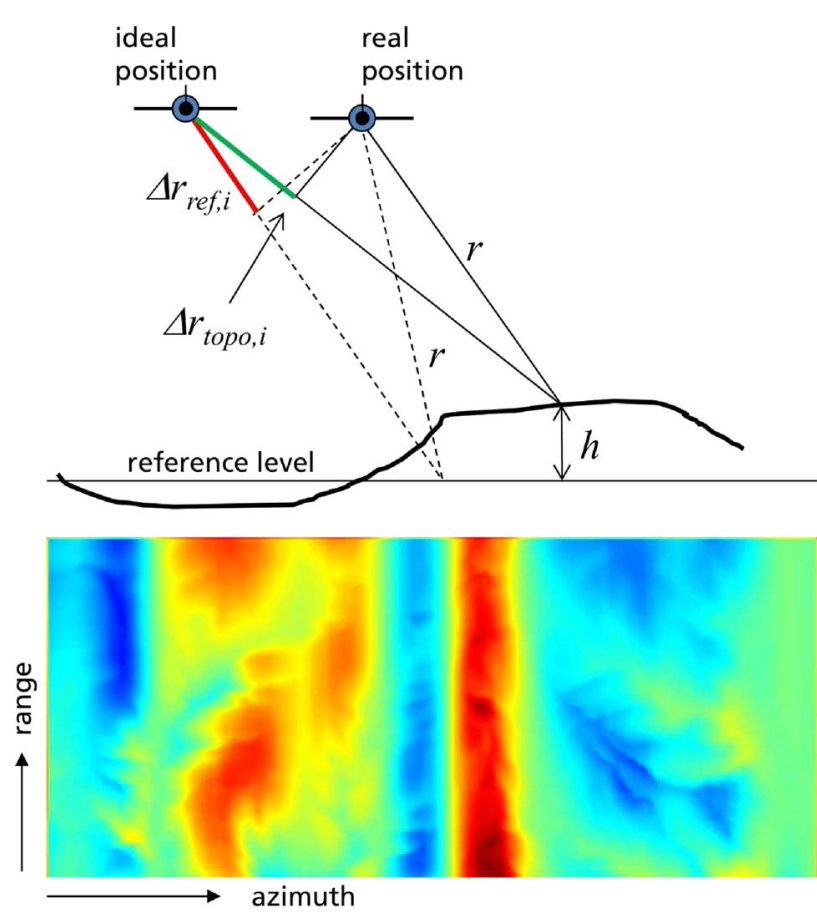

Fig. 5. Range difference for motion compensation using a reference level (approximated, default during 2-D focusing) and assuming the topography (exact, when using topography adaptive approaches). Example for topography-dependent phase error for a mountainous area. Note the coupling between topography and motion errors along azimuth. are encountered for the different interferometric acquisitions $i$, with $\lambda$ denoting the radar wavelength, $r$ the range distance, $x$ the azimuth position, and $\Delta r_{\text {ref/topo }}$ the path length difference between the real and ideal (reference) tracks, calculated for a reference height or considering topography, respectively.

In general, the error amounts to several phase cycles, as exemplified in Fig. 5. For L-band at a flight altitude of $3000 \mathrm{~m}$ and a deviation from the ideal track of $5 \mathrm{~m}$, the phase error amounts to approximately $2 \pi$ for every $100-\mathrm{m}$ height difference from the reference level. Note that the topographic motion compensation is also azimuth aperture dependent and, therefore, it also compensates variable azimuth shifts and improves the focusing. Therefore, it ideally augments all 2-D frequency-domain SAR processing algorithms leading to higher quality data even if interferometry is not required. For the time-domain approaches discussed in Section III-B, topography is considered inherently.

2) Estimation and Correction of Residual Motion Errors: The performance of standard airborne SAR processing is limited by the accuracy of the navigation data available to perform the motion compensation [state of the art is a combination of inertial unit and Global Positioning System (GPS) sensor]. Although the relative accuracy is very good, enabling well-focused data, the absolute performance is limited by the absolute precision of the differential GPS signal, which is in the order of 5-10 cm (up to one interferometric phase cycle assuming SAR data at L-band and the two-way propagation delay). It is obvious that this accuracy is insufficient for repeat-pass interferometry. A robust error estimation approach has been developed based on the so-called multisquint technique [50], [51]. It can be understood as the measurement of azimuth misregistration values, which are then inverted to yield derivatives of the horizontal and the vertical baseline offsets, which are finally integrated to serve as inputs for computing an azimuth varying phase correction (see Fig. 6). For a single range position, the approach can be summarized as

$$
\Phi_{\text {err,res }}(r, x)=\frac{4 \pi}{\lambda r} \int \Delta x(r, x) d x
$$

where $\Delta x$ stands for the range/azimuth-dependent misregistration in azimuth.

In the multisquint technique, phase differences of interferograms obtained from multiple spectral looks are computed, averaged, and then inverted to give robust estimates of residual baseline errors while considering coherence weights. Generally, it can be stated that the technique has some similarity to the assessment of variable azimuth movement, e.g., of glaciers in spaceborne SAR 


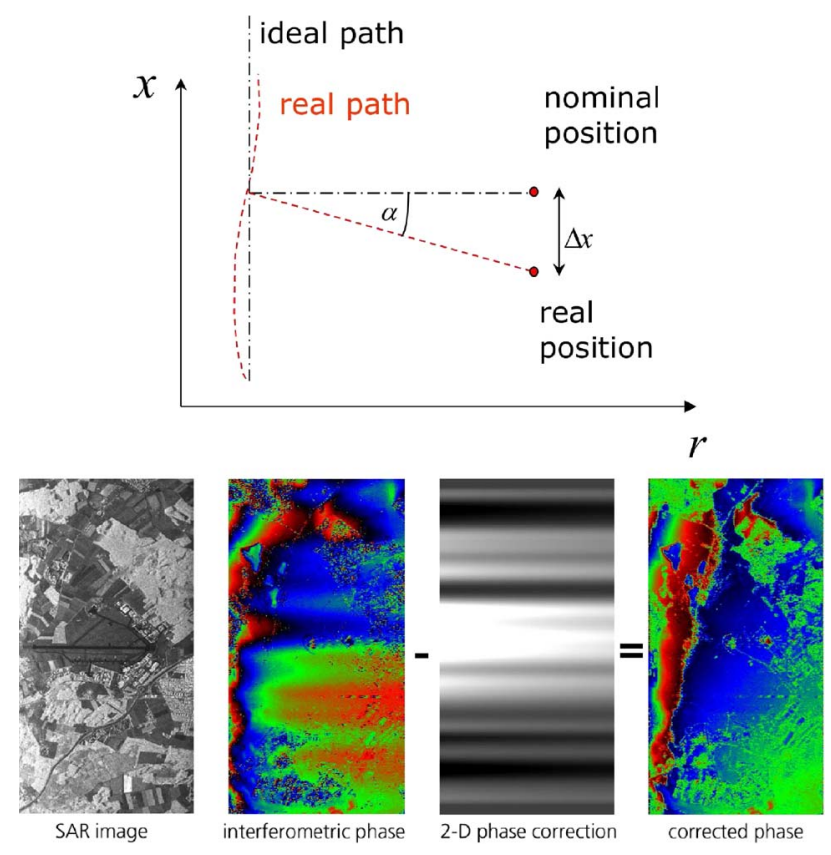

Fig. 6. Linear (residual) motion errors lead to azimuth varying misregistration in interferometric SAR (top). The applied phase corresponds to the integration of the estimated azimuth localization error [see (2)]. Early example for repeat-pass case in L-band (bottom).

interferometry using spectral diversity [52], [53]. The technique is also referred to as multiaperture interferometry (MAI) [54]. An example of successful compensation is shown in the lower part of Fig. 6. However, note that similar to the topography compensation, it is not sufficient to simply add the computed phase correction to the slave data. Moreover, it is essential to decompress, compensate, and recompress the data in azimuth in order to correct also the second-order effects (wrong localization and potential azimuth defocusing due to the range misregistration variation in the original raw data).

The accommodation of this technique within the interferometric SAR processing chain including topography adaptive motion compensation is shown in the block diagram in Fig. 7. It is important to remark that topography adaptive motion compensation is required to be performed prior to the residual baseline error estimation in order to avoid the misinterpretation of the estimates. Further, the nominal coregistration only considers the known acquisition geometry, possibly refined by a constant offset estimated from the data.

With multisquint, the differential residual motion errors (in horizontal and vertical directions) between the two tracks are inverted from the estimated residual phase [see (2)]. The estimation is repeated by iteratively processing the slave image. This process avoids underestimating the residual errors due to the limited coherence of the scene and gives confidence to the retrieved estimates [51]. An example of residual errors estimated for C-band data

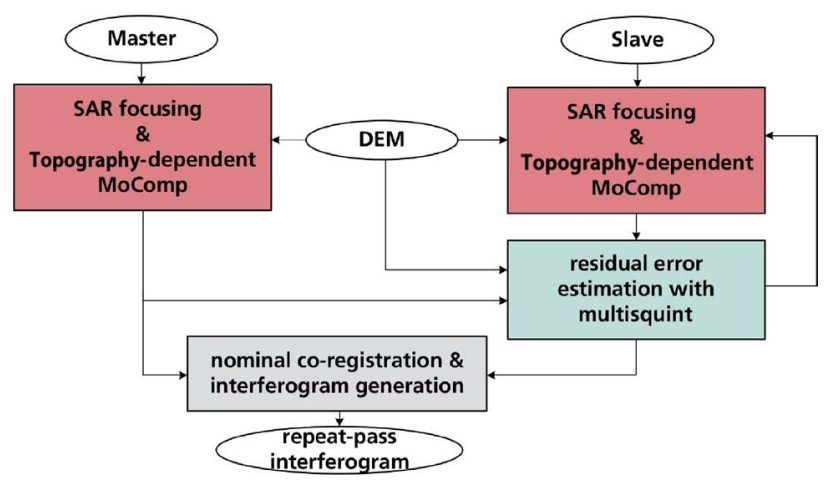

Fig. 7. Interferometric processing of airborne data including 2-D SAR focusing algorithm with integrated topography adaptive motion compensation and multisquint processing for residual motion error estimation.

with millimeter accuracy is shown in Fig. 8. Without this compensation approach, phase errors and coherence degradation would occur, impacting seriously the interferometric data quality. In case of azimuth motion (e.g., glacier flow), an extended multisquint approach has been developed, which decouples residual motion errors from the real movement in the scene (see Section IV-C and [55]).

As an alternative to the multisquint techniques, advanced autofocus algorithms may also be considered for
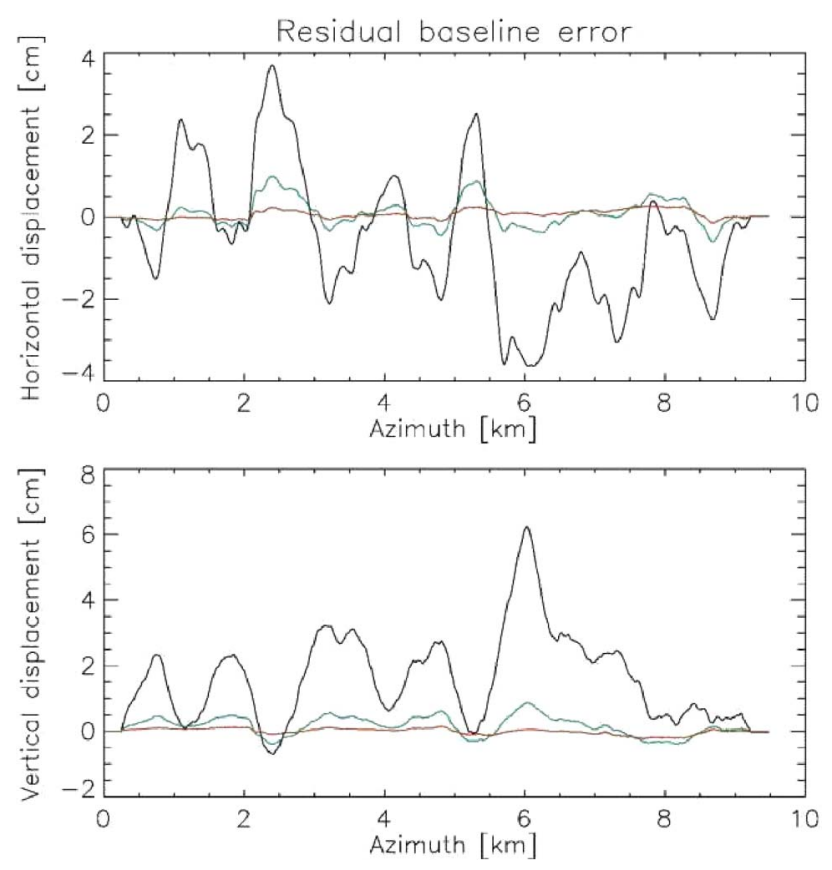

Fig. 8. Residual motion errors between master and slave images estimated by the iterative multisquint approach for a C-band interferometric pair of E-SAR data. Black: Original residual errors; green: After one iteration; red: After three iterations. Top: Horizontal error; bottom: Vertical error. 
estimating and compensating independently the residual motion errors of master and slave images. For example, the weighted phase curvature autofocus (WPCA) algorithm was shown to be suitable for multipass airborne SAR interferometry at L-band [56].

\section{Accounting for Sensor Hardware}

The signal processing pipeline outlined in Fig. 2 makes the basic assumption that SAR raw data can be compressed in range with a known reference function, i.e., the pulse transmitted by the sensor. The obvious requirement that this reference function be characterized with high precision introduces another aspect to SAR signal processing: high-quality image formation requires precise knowledge of the behavior of the numerous hardware components in the transmit and receive signal pathways.

In practice, modern sensors include a special replica signal pathway [57], [58], in which the output of the transmit signal pathway is fed directly into the receive pathway. The signal thereby recorded then characterizes the combined impulse response of all sensor components and, if measurements are taken regularly during data acquisition, includes transient phenomena, such as temperature variations, which are difficult to model or measure otherwise. Importantly, these internal measurements cannot account for characteristics of the transmit and receive antennas. The response of an antenna varies significantly as a function of propagation direction in 3-D space. Consequently, an appropriate treatment of the antenna in processing is both important and, in practice, challenging.

At the outset, the antennas in a SAR system must be characterized precisely in the form of a 3-D model over two angles (elevation and squint) and frequency. In practice, such models are obtained either from simulations [59], direct far-field measurements [60], or, with limited accuracy, from the analysis of acquired SAR data.

The most well-known feature of an antenna is its overall gain, i.e., the amplification of signals in transit, as a function of propagation direction. The overall gain over elevation plays a central role in the radiometric calibration of data and will be dealt with separately in Section III-E. Traditionally, other effects have been neglected. As the bandwidth of SAR sensors increases, however, this assumption no longer holds as it becomes prohibitively difficult to design antennas that are sufficiently well behaved over an increasingly large frequency range. An example of an effect that may need to be considered is a gain that varies as a function of frequency and, potentially, propagation direction. Unless compensated for, this misestimation of the sensor impulse response leads directly to a loss of resolution. Another example, which has not in fact been observed in F-SAR data, would be a signal delay that varies as a function of propagation direction and would impair the geometric accuracy and, potentially, the resolution.

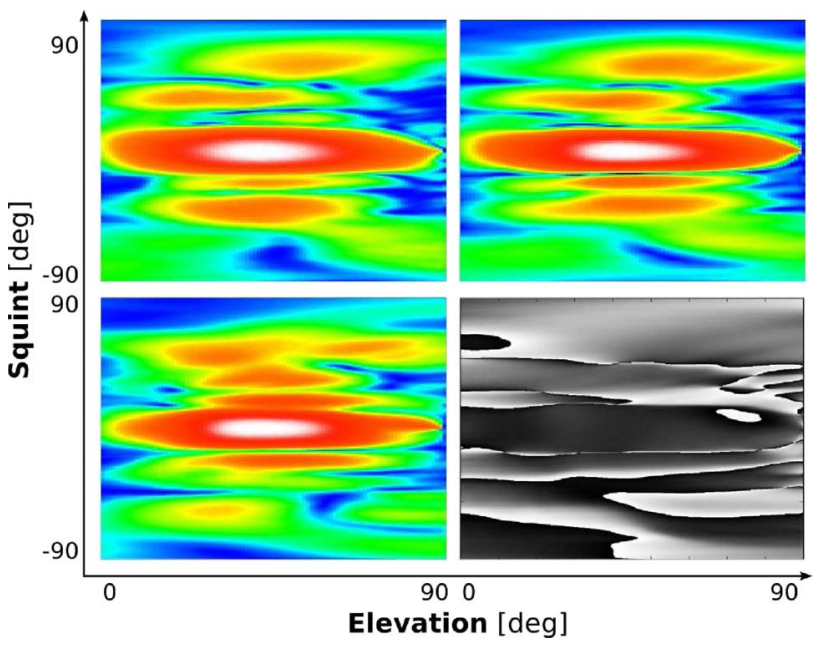

Fig. 9. Clockwise from the bottom left: The antenna gain $\mathrm{A}(\theta, \phi)$ of the F-SAR S-band $H$-polarized antenna at three frequencies within the processed bandwidth (300 $\mathrm{MHz})$. Bottom right: The antenna phase at the center frequency $f_{0}=3.25 \mathrm{GHz}$. All plots illustrate variations as a function of the squint and elevation angles and contain information that is crucial for accurate sensor calibration.

The former example is illustrated in Fig. 9, where the antenna gain clearly varies over the sensor bandwidth. As it happens, the associated antenna impulse response is also variable with respect to the elevation angle, as is evident in the slight resolution trend of Fig. 10. Since the antenna impulse response is therefore a function of time (elevation angle as a function of range time) and frequency, the correction must be carried out using time-frequency techniques such as the short-time Fourier transform [61]. The results of the correction, which was carried out as a

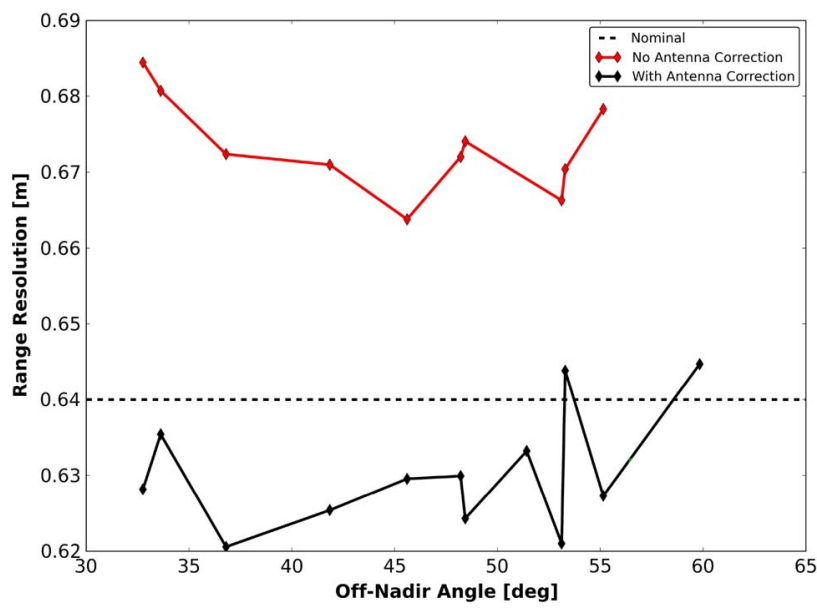

Fig. 10. The range resolution of F-SAR S-band data, in HH polarization, as a function of the off-nadir angle. The resolution is measured on trihedral corner reflectors and can be seen to improve once the impulse response function of the antenna has been taken into account. 
postprocessing step, show that the nominal sensor resolution can be restored (see Fig. 10).

\section{E. Radiometry and Phase Calibration}

The calibration of a SAR sensor ensures that all data products produced by the processor are associated with well-defined, physical units and can therefore be meaningfully compared and interpreted as absolute values. The intensity of a SAR image, for instance, usually denotes the radar backscattering coefficient of the imaged targets and can be linked to quantitative estimates of soil moisture [62]. The phase of a complex SAR image, meanwhile, is essential as a measure of sensor-to-target distance in InSAR applications (as, for example, in Section IV-C) and plays an equally fundamental role in the derivation of polarimetric signatures in PolSAR applications.

Sensor calibration is generally a two-step process [63], the first of which is internal and derives necessary adjustments to image magnitude, phase, and range distance at which targets are imaged from known properties of the sensor (i.e., the sensor impulse response function discussed in Section III-D) and the imaging geometry. In the external calibration that follows, these adjustments are validated based on reference targets with known properties, such as dihedral or trihedral reflectors or transponders, and additional corrections are derived. The aim of the internal calibration is to ensure that these corrections apply even after the internal configuration of the sensor or the imaging geometry have changed, such that calibrated data can be produced without having to rely on reference targets in the imaged scene.

The internal calibration of SAR image intensity is based on the radar equation for SAR, which relates the radar cross section $\sigma$ to the power received by the sensor $P_{R}$ and is usually written [64]

$$
P_{R}=\sigma \frac{P_{T} G_{\text {sys }} G_{\text {proc }} \lambda^{3} A(\theta) f_{\mathrm{r}}}{(4 \pi)^{2} r^{3} 2 \delta_{a z} v}
$$

where $P_{T}$ is the power transmitted, $G_{\text {sys }}$ is the accumulated gain of all components in the transmit and receive signal paths, $G_{\text {proc }}$ is the gain due to the SAR processor (it includes, for instance, the effect of the windowing functions used for sidelobe suppression), $\lambda$ is the system wavelength, $A(\theta)$ denotes the two-way antenna gain as a function of the elevation angle $\theta$ of a given target, $f_{\mathrm{r}}$ is the pulse repetition frequency, $r$ denotes the range distance to the target, $\delta_{a z}$ is the azimuth resolution and $v$ is the platform velocity.

For VHR airborne SAR data, the computation of $\sigma$ by rearranging (3) is problematic, since it does not explicitly account for deviations from the nominal track or the real sensor attitude angles during the acquisition. In addition, it does not account for the fact that $r$ and $\theta$ are not, in fact, constant but vary within the synthetic aperture. Taking these effects into account becomes especially important as the resolution increases and longer integration times necessarily lead to larger variations within the aperture.

An extended version of (3) that takes these effects into account can be written [61]

$$
P_{R}=\sigma \frac{P_{T} G_{\text {sys }} \lambda^{2}}{(4 \pi)^{2}} \sum_{t=t_{0}}^{t_{1}} \frac{G_{\text {proc }}(t) A(\theta(t), \phi(t))}{r(t)^{4}}
$$

where $t_{0}$ and $t_{1}$ denote the start and stop, in samples, of the integration time for a given target, $G_{\text {proc }}$ now varies with integration time due to the azimuth sidelobe suppression window, $A(\ldots)$ denotes the $2-\mathrm{D}$ two-way antenna gain as a function of elevation $\theta$ and squint $\phi$, and the range distance $r$ changes as the sensor moves toward or away from the target. The maps $\theta(t)$ and $\phi(t)$ take into account the sensor attitude angles (heading, pitch, and roll) to map a given target into the 2-D antenna coordinate system. Finally, the radar cross section can be recovered by carrying out the summation over samples $t$ numerically and rearranging for $\sigma$. Fig. 11 shows that this approach can lead to considerably more stable radiometric calibration results than the simpler alternative in (3).

Assuming that a complex, 3-D antenna pattern $a(\theta, \phi, f)$ over elevation, squint, and frequency is available, it becomes possible to precisely remove residual phase variations from the data. These variations arise when the phase center of an antenna is not a single point in 3-D space, but moves as a function of the direction of propagation (see the phase variations in Fig. 9). This phase

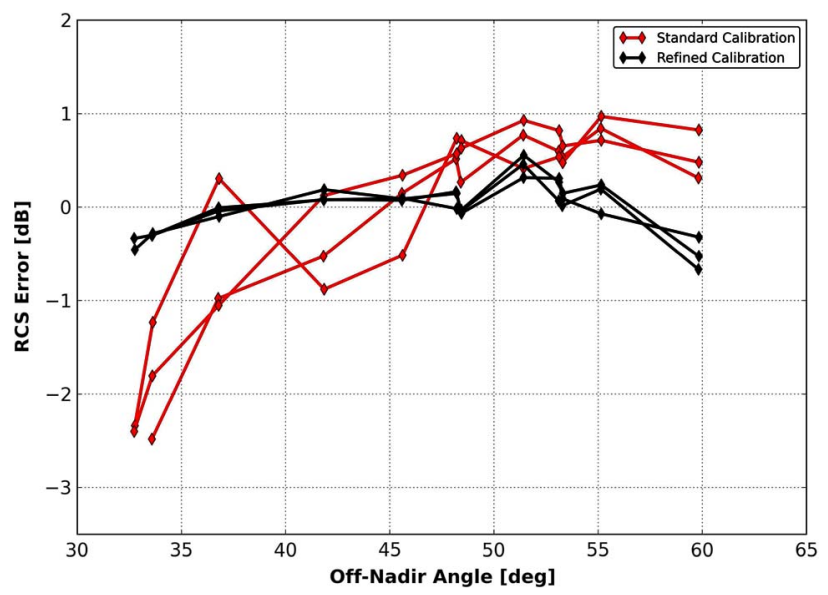

Fig. 11. A comparison of calibration algorithms for X-band F-SAR data using trihedral corner reflectors in three independent acquisitions. The RCS error shown denotes the difference between the theoretical and measured radar cross sections. Red: Standard calibration; black: Refined calibration with 3-D antenna model. 
This article has been accepted for inclusion in a future issue of this journal. Content is final as presented, with the exception of pagination.

Reigber et al.: Very-High-Resolution Airborne Synthetic Aperture Radar Imaging

Table 3 The Effect of Phase Corrections Derived From the Complex Antenna Characterization for Data Acquired by the F-SAR Sensor in $X$ - and S-Bands. The Standard Deviations Represent the Variation of the Polarimetric HH-to-VV Phase Difference Measured on Trihedral Corner Reflectors in a Number of Independent Acquisitions. The Phase Accuracy Is Seen to Improve by About $20 \%$ in Each Case. High Phase Accuracy Is Required for Polarimetric and Interferometric Applications

\begin{tabular}{|c|c|c|}
\hline Band & $\begin{array}{c}\sigma\left(\Phi_{H H}-\Phi_{V V}\right) \\
\text { (original) }\end{array}$ & $\begin{array}{c}\sigma\left(\Phi_{H H}-\Phi_{V V}\right) \\
\text { (corrected) }\end{array}$ \\
\hline$X$ & $2.5^{\circ}$ & $2.0^{\circ}$ \\
\hline $\mathrm{S}$ & $2.3^{\circ}$ & $1.9^{\circ}$ \\
\hline
\end{tabular}

contribution can be estimated and consequently removed by evaluating an integral very similar to that of (4)

$$
\Phi_{\text {ant }}=\arg \left[\sum_{t=t_{0}}^{t_{1}} \frac{\sqrt{G_{\text {proc }}(t)} a\left(\theta(t), \phi(t), f_{0}\right)}{r(t)^{2}\left|a\left(\theta(t), \phi(t), f_{0}\right)\right|}\right] .
$$

This equation expresses the fact that the phase in the focused SAR image is given by the weighted summation of complex amplitudes with phase information originating at the center frequency $f_{0}$ of the sensor. Table 3 suggests that this type of phase correction can improve the phase stability of the focused SAR images in the context of PolSAR analyzes. Similar improvements are to be expected in InSAR applications.

\section{APPLICATIONS OF HIGH-RESOLUTION SAR}

\section{A. VHR Polarimetric Imaging}

One of the main drawbacks of SAR data, when compared to optical data, is the inherent presence of speckle noise in the images. In medium resolution images, natural surfaces and other distributed targets appear blurred and noisy to the untrained observer, who has typically the feeling to analyze an image of much lower resolution or quality than it actually has. Only on pure point-like or linear targets with strong reflection (typically man-made structures or vehicles) the real resolution capabilities of SAR are fully developed. However, once the sensor's spatial resolution, and associated, the speckle's granularity scale, reaches values significantly below the size of objects to be analyzed, the effect of speckle backs out and even fine details, like, for example, textures on distributed targets, can be examined.

Other typical problems when interpreting conventional SAR images occur in the case of, for example, urban areas. The footprint of buildings is generally not correctly imaged, since a SAR works in a side-looking geometry, causing strong layover and shadowing effects. Usually, only an L-shape of the building parts facing the radar is recovered. Additionally, parts of the roof areas appear often very dark due to their inappropriate orientation toward the sensor. Both effects together render the interpretation of urban areas and buildings in general to be a complicated task, which usually requires several images from different geometries.

Recent airborne SAR sensor systems have advanced into the decimeter resolution range, which apparently is high enough to cover many requirements of Earth observation applications, even when considering a certain deficit in image interpretability due to speckle. Additionally, the availability of polarimetric information makes it possible to generate false color images and especially to image also urban structures in a much more convenient way, since polarization diversity helps circumventing orientation effects. Such an imagery delivers an almost photographic impression of the scene under investigation, and interpretation becomes comparatively easy even for untrained users.

Fig. 12 shows a fully polarimetric X-band F-SAR image with $25-\mathrm{cm}$ resolution of a small farm with surrounding agricultural surfaces. The buildings in the middle of the scene are well imaged, particularly the roof areas show a strong response in the cross-polar channel due to their orientation to the sensor. The different fields appear in various colors, depending on their respective crop types. Some of the surfaces show significant growth effects (e.g., the dark spot in the top left of the image), being an indication of variations in moisture and/or soil quality. Very important is also the observation that at this resolution surface textures become apparent in SAR images. This is most obvious in the yellow/ocher field in the top middle of the image: here machining has generated a linear texture

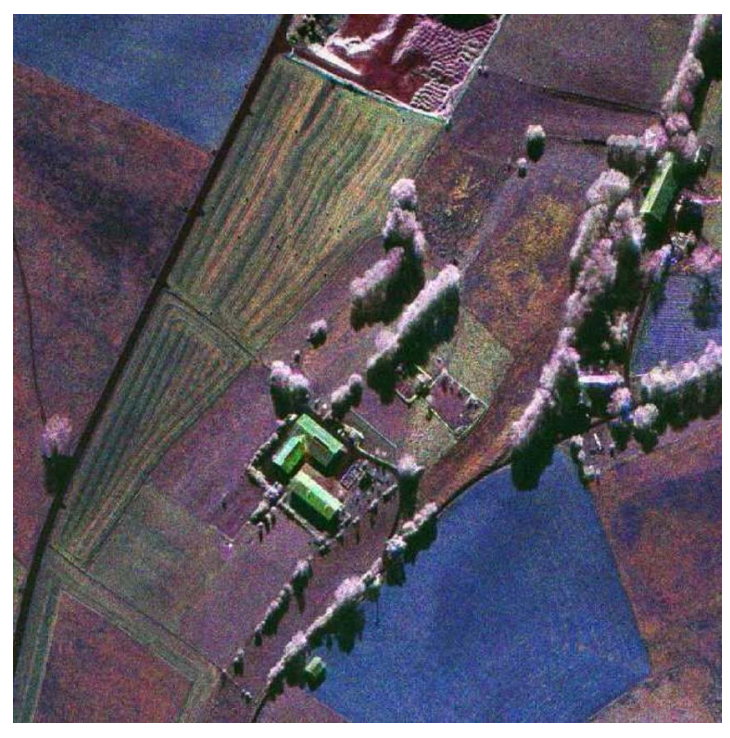

Fig. 12. Fully polarimetric F-SAR X-band image with 25-cm spatial resolution (blue: $\mathrm{VV}$ polarization, red: $\mathrm{HH}$ polarization, green: $\mathrm{HV}$ polarization). Building shapes and surface textures are clearly visible. 


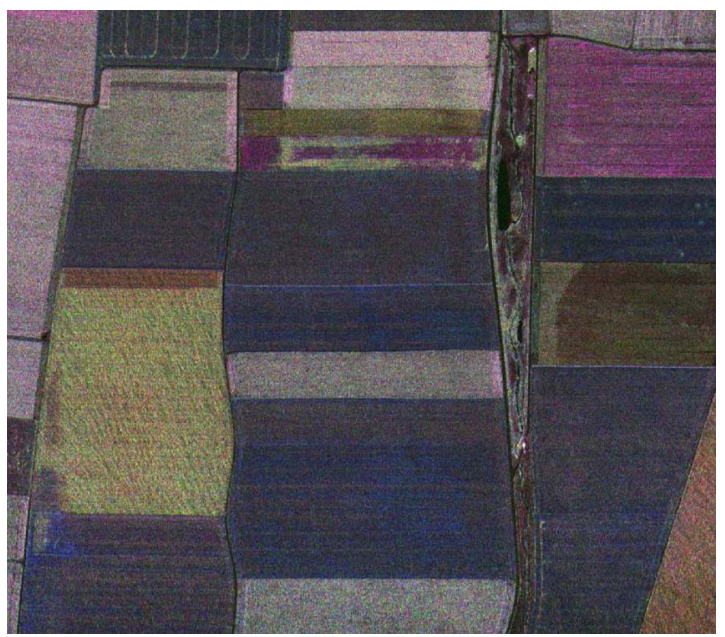

Fig. 13. Surface textures and wind blow effects in an agricultural area. Image acquired by F-SAR in C-band with $50-\mathrm{cm}$ resolution (blue: VV polarization, red: HH polarization, green: HV polarization).

across the field; even some small haystacks are visible. Also the blue field in the middle right shows a significant linear texture.

Another example of a fully polarimetric high-resolution image can be found in Fig. 13. This image has been acquired at C-band, a wavelength often considered to be ideal for agricultural applications. At a spatial resolution of $50 \mathrm{~cm}$, various surface textures can be observed. Particularly, the yellow field in the middle left shows wind blow effects overlaid to a light horizontal linear texture corresponding to the orientation of the planting. Also several of the other fields show interesting textures. Up to now, surface textures in SAR imagery have widely been ignored. However, they provide an additional and valuable source of information, allowing, for example, to distinguish or recognize certain surface types with an otherwise similar signature.

S-band is a very attractive wavelength, since it already shows significant penetration capabilities into vegetation and strong polarimetric effects. At the same time, still very high spatial resolutions can be achieved at S-band. Fig. 14 shows a high-resolution S-band image acquired by F-SAR. Particularly, the forest is imaged with great detail. If examined carefully, one can observe some individual trees along the railroad line in the middle of the scene, which appear semitransparent due to the penetration capabilities of longer microwaves at S-band.

At L-band, spatial resolution is lower, due to the long wavelength and the small available bandwidth according to frequency regulations. However, polarimetry is know to be strong at L-band,and even dense forest is penetrated up to the ground. Fig. 15 shows a high-resolution L-band image of a partly forested area, with some rotating windmills in the open areas. The coarse texture of the forest canopy is

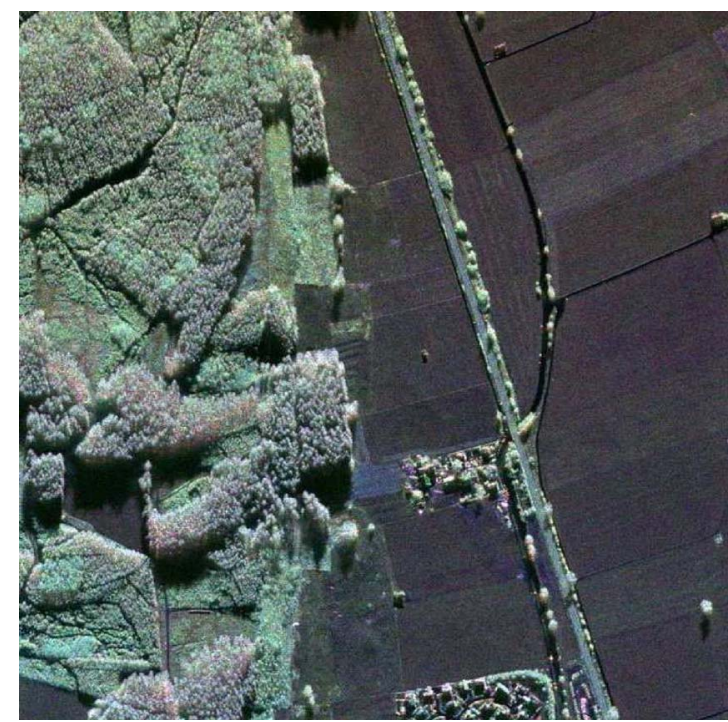

Fig. 14. Agricultural area and an alley of trees, appearing semitransparent at S-band. Image acquired by F-SAR in S-band with $65-\mathrm{cm}$ resolution (blue: VV polarization, red: $\mathrm{HH}$ polarization, green: $\mathrm{HV}$ polarization).

visible, while the rotating wings of the windmills appear defocused due to the long integration time.

\section{B. Change Detection}

A broad class of SAR applications is based on the ability to detect temporal changes in an area of interest that is repeatedly, perhaps even routinely, imaged by SAR sensors. Examples include the monitoring of land use to detect

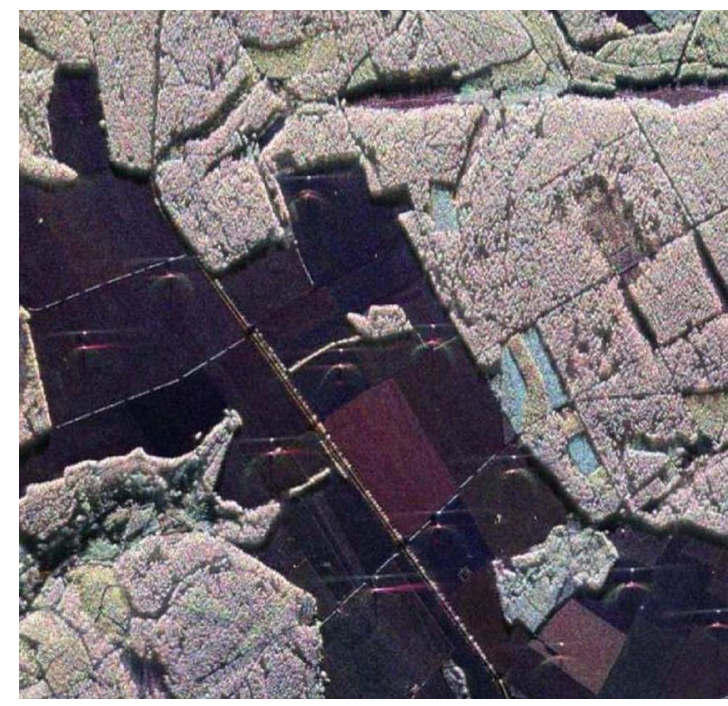

Fig. 15. Rotating windmills close to some forested areas. Image acquired by F-SAR in L-band with $1.5 \times 0.5-\mathrm{m}^{2}$ resolution (blue: VV polarization, red: HH polarization, green: HV polarization). 
This article has been accepted for inclusion in a future issue of this journal. Content is final as presented, with the exception of pagination.

Reigber et al.: Very-High-Resolution Airborne Synthetic Aperture Radar Imaging

seasonal or other changes, rapid damage assessment in the wake of natural disasters, and surveillance.

High-precision interferometric SAR processing, as described in Section III, provides fully automatic means for generating SAR image pairs or image stacks that are coregistered with centimeter precision. In addition to techniques for interferometric analysis, these data can be compared and exploited to detect changes such as object movement or local changes in the observed dielectric properties. The availability of VHR SAR data means that even small-scale changes, such as moving vehicles or damage to infrastructure, can be identified.

Approaches to change detection generally fall into three categories: straightforward approaches on the basis of single-channel intensities, coherent interferometric change detection, and incoherent change detection on the basis of polarimetric signatures.

In contrast to the straightforward comparison of image intensities, coherent change detection relies crucially on the so-called interferometric coherence. This quantity $\gamma$ is defined as the normalized cross correlation of the complex master and slave images. Decorrelation between acquisitions, associated with a low coherence, indicates that change has taken place. Significantly, the coherent nature of the approach allows for the detection of changes that have only negligible impacts on the backscattered intensity: as the observed pixel amplitude and phase are sensitive to the spatial arrangement of all scattering contributions within a resolution cell, coherent change detection can potentially detect extremely subtle scene changes. This, of course, also implies a high sensitivity to environmental effects such as wind and rain, which may be irrelevant to the application at hand.

Such applications can benefit from incoherent polarimetric change detectors. These are based on the comparison of the polarimetric signatures observed at different acquisition times. The polarimetric properties of a target are known to be highly sensitive to its size, shape, geometrical structure, and dielectric properties. At the same time, polarimetric signatures are not sensitive to the spa- tial arrangement of scattering mechanisms within a resolution cell, such that detection results are not affected by interferometric decorrelation.

The polarimetric change detector derived in [65] has proven useful in a number of applications. It defines an indicator of change

$$
\Gamma=\frac{\left|C_{1}\right|^{N}\left|C_{2}\right|^{N}}{\left|\frac{\left(C_{1}+C_{2}\right)}{2}\right|^{2 N}}
$$

where $C_{1}$ and $C_{2}$ denote the $N$-look sample covariance matrices in images 1 and 2 , respectively, and $|\cdot|$ denotes the matrix determinant. The detector has the advantage of being very robust and, if used in conjunction with the associated test statistic, has a constant false alarm rate with respect to the statistics of polarimetric speckle noise.

An example of high-resolution intensity-based change detection is shown in Fig. 16. Here, a parking lot of a logistics company was imaged twice within about one hour with the F-SAR airborne instrument in high-resolution $\mathrm{X}$-band mode. A number of cars and trucks have evidently appeared (blue) or disappeared (yellow) in the time between data acquisitions. Fig. 17 shows a comparison of coherent interferometric and incoherent polarimetric change detection. The coherent detector, shown on the left, is very sensitive to even the smallest changes such as movements in wind blown vegetated areas. In contrast, the polarimetric detector robustly identifies changes in polarimetric signatures, which can, in this example, be attributed mainly to moving vehicles.

\section{DInSAR Applications}

Differential SAR interferometry (DInSAR) has become a powerful tool to measure deformation phenomena at a large scale [66], [67]. Very high accuracy, in the order of a fraction of the wavelength, can be attained by exploiting the coherent nature of SAR systems. Differential SAR

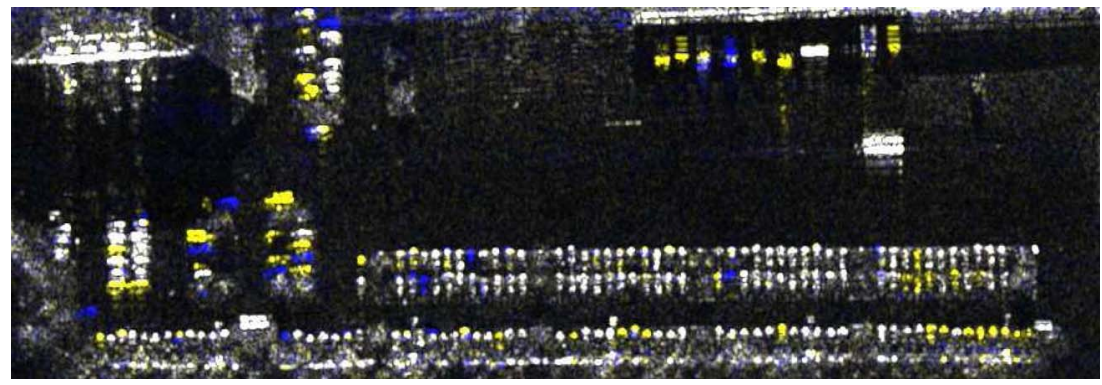

Fig. 16. Monitoring the parking lot of a logistics company using intensity-based change detection. Two images with a multilook resolution of $0.5 \times 0.5 \mathrm{~m}^{2}$ were acquired with 2-h separation. Changes appear in blue and yellow, and white represents vehicles that have not moved between both acquisitions. 

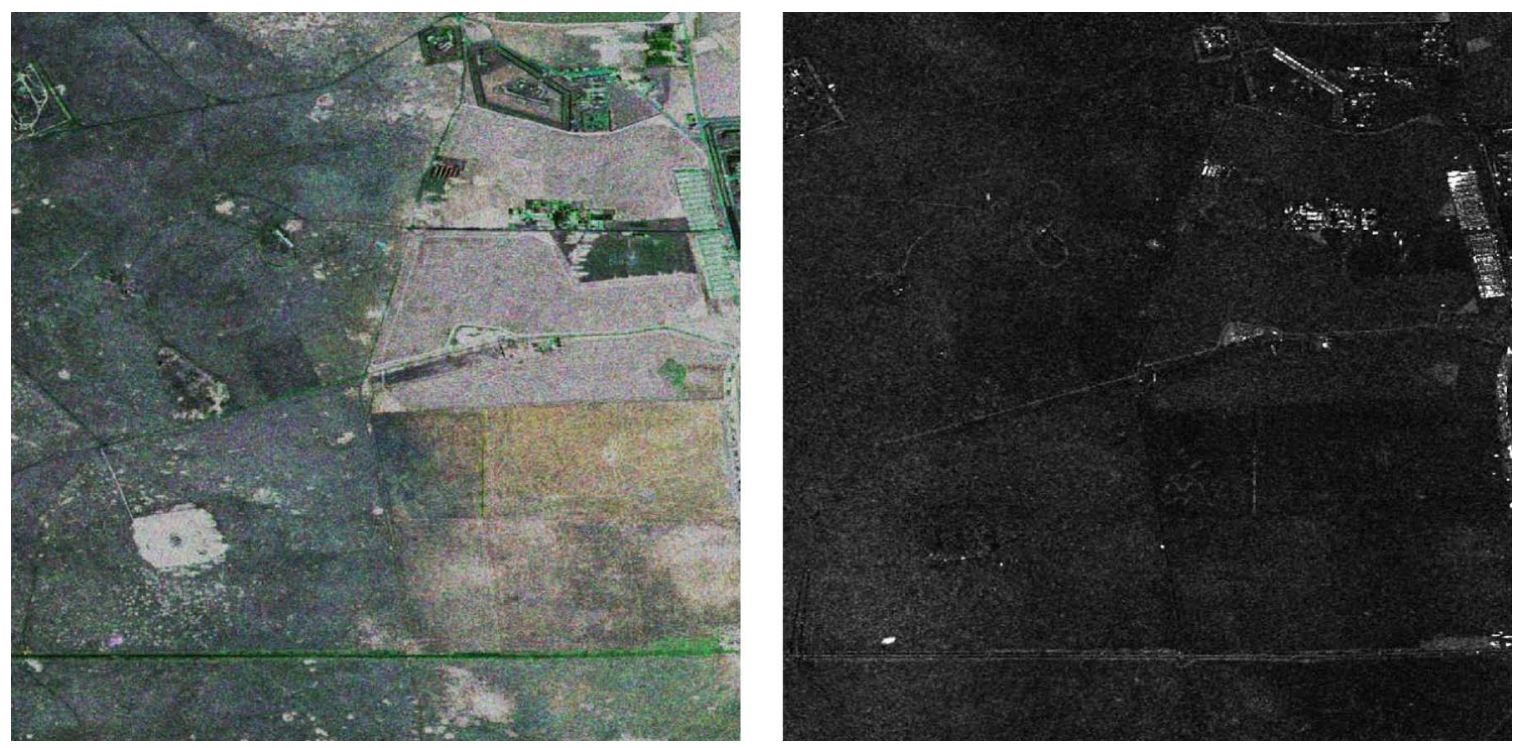

Fig. 17. Change detection in two high-resolution F-SAR X-band scenes acquired with about two days time difference; bright patches indicate high probability of change. Left: Coherent detection based on interferometric coherence (blue: VV polarization, red: HH polarization, green: HV polarization). After two days, mainly phase decorrelation within different vegetation types dominates. Right: Incoherent polarimetric change detection, indicating primarily the vehicles that moved between data acquisitions.

interferometry using a spaceborne platform is already an established technique. The ideal stable trajectory of a satellite ensures that the SAR processor will be able to properly focus the data without introducing undesired artifacts. Also, the fact that large stacks of images are available for most areas of interest has been of great help to develop several advanced DInSAR (ADInSAR) techniques [10], [68]-[70]. The airborne data processing represents a further challenge, since it is subject to the limitations imposed by motion compensation, as already mentioned in Section III-C. However, the advantages an airborne platform can offer are quite appealing: flexibility in sense of spatial resolution, used wavelength, and data acquisition (i.e., short revisit time). For example, the radar frequency plays an important role regarding temporal coherence and ground penetration, since lower frequency bands (L, P) tend to have a better long-term coherence and higher ground penetration than higher frequency bands. Also, the flexibility of the data acquisition is a major asset, since the aircraft can be used to acquire the images with the desired time intervals and geometries, not having to wait, as it happens in the orbital case, for the satellite to illuminate the same area with a similar look angle.

Several papers have been published in the past concerning airborne DInSAR. In 2003, the first airborne differential SAR interferogram of a large area was presented in [71], using a classical three-image DInSAR approach [72]. The authors measured some displacements in agricultural fields that might be related to the penetration depth of electromagnetic waves due to a different soil moisture, and also obtained indication of water level change in a swamp area. In 2004, some controlled experiments with three corner reflectors measured at both L- and C-bands were presented in [73], obtaining absolute measurements with an accuracy better than $1 \mathrm{~cm}$. Also in 2004, the deformation of a dike measured at C-band was reported in [74]. In 2008, a time series at X-band was presented in [75], where the motion of a corner reflector was retrieved, while in the same year, a time series at L-band was analyzed in [76], where several differential effects could be observed over agricultural fields.

As a further example of airborne differential SAR interferometry, Fig. 18 shows the estimated ground deformation in a mining area in Germany. The data were acquired in 2009 by the E-SAR system at L-band with a separation of six months. Despite the large temporal

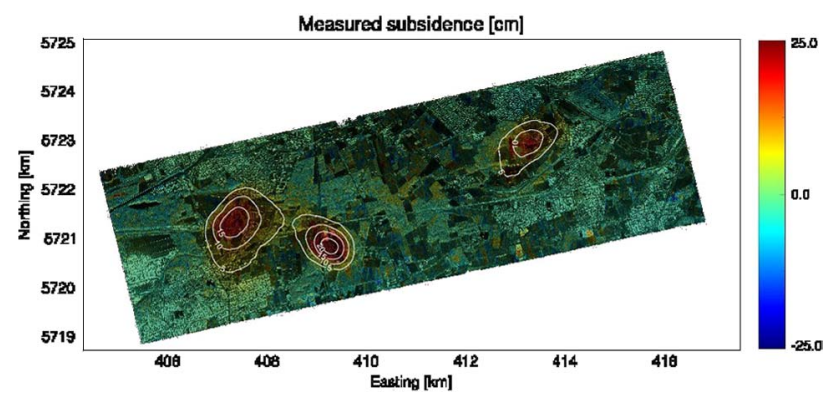

Fig. 18. Estimated ground deformation with overlayed reflectivity over a mining area in Germany. Data acquired by the E-SAR system at L-band with six-month separation. 
separation, the coherence is still good, allowing the retrieval of valuable deformation information, even over vegetated areas. Note also that the high resolution of the system, about $2 \times 0.5 \mathrm{~m}^{2}$ (range $\times$ azimuth) in the current case, allows for a larger averaging window, hence achieving a better phase noise reduction but still delivering a product with a good geometric resolution. Note that the subsidence reaches up to $20 \mathrm{~cm}$ in some areas.

Another example in terms of data acquisition flexibility is given in the monitoring of alpine glaciers. Due to the data scarcity, as well as the lack of field measurements in such high-altitude and remote scenarios, remotely sensed SAR data become an attractive alternative. Spaceborne SAR systems have already proven the possibility to measure the surface velocity field (SVF) of glaciers [77]-[82], but the lack of flexibility in the acquisition configuration as well as the fixed, and usually too large, revisit time, is an important limitation in many cases. Airborne SAR systems are, however, not limited by this factors. Furthermore, by using short revisit times, one can use coherent interferometric techniques to measure the SVF, which, besides being more accurate when there is coherence, do not rely on texture, hence being feasible also in areas with homogeneous backscattering.

Fig. 19 shows the estimated 2-D SVF over the Aletsch glacier using the E-SAR sensor. The campaign was flown in 2006 at X-, L-, and P-bands in two consecutive days [55]. The motion in line-of-sight (LOS) was estimated using
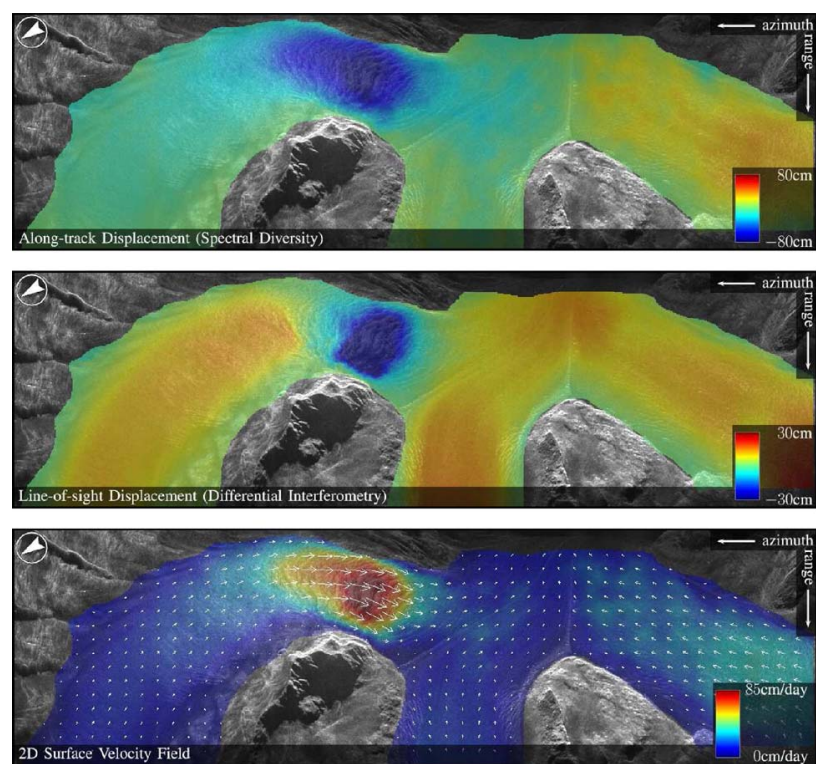

Fig. 19. Retrieval of the 2-D surface velocity fields over the Aletsch glacier at L-band. Top: Along-track displacement measured by means of estimating the mutual shift between images. Middle: LOS displacement measured by means of DInSAR. Bottom: Combination of both measurements, where the colors indicate the magnitude and the arrows indicate the direction of the displacement. Scene dimensions: $7.6 \times 1.9 \mathrm{~km}^{2}$ (azimuth $\times$ slant range).

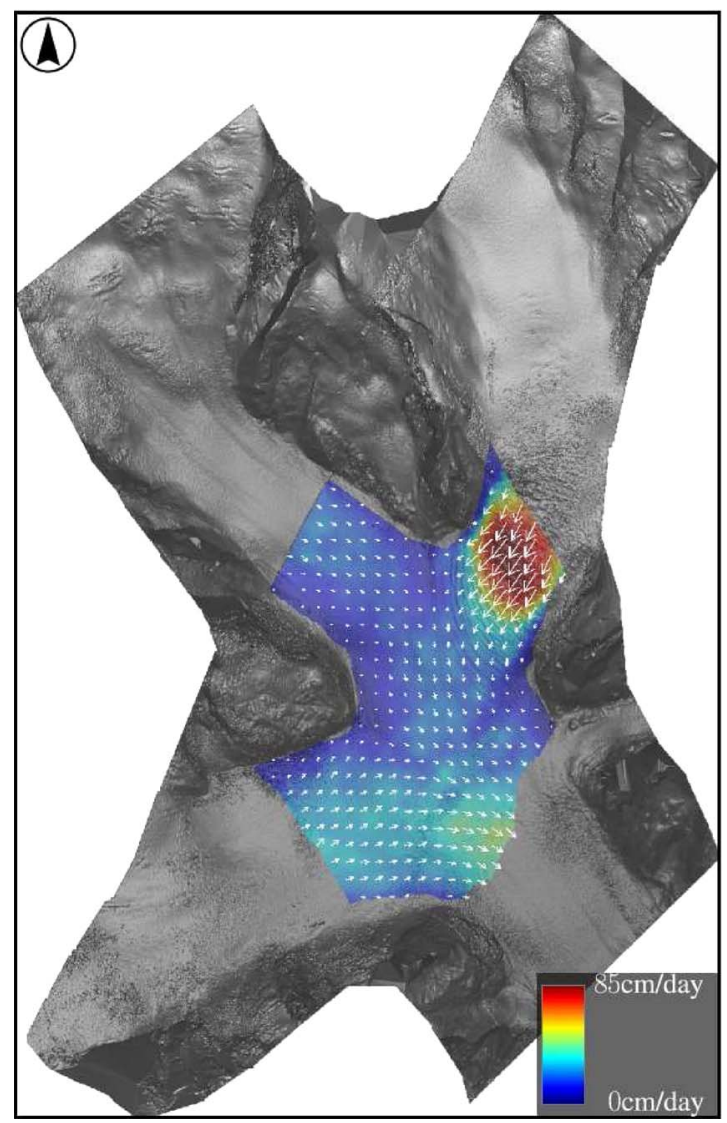

Fig. 20. Estimated 3-D surface velocity field at L-band, derived from the combination of two orthogonal passes over the Aletsch glacier.

DInSAR. To measure the along-track displacement (mutual shift), the so-called spectral diversity technique [52] was used, which achieves the Cramér-Rao bound in the estimation of the coregistration error [83]. Under the surface parallel flow assumption [81], the 3-D SVF can be retrieved by projecting the 2-D one using the terrain slope, which in the present case was computed with the X-band DEM obtained in the single-pass mode. Furthermore, the E-SAR system was also flown orthogonally to the first pass, so that different projections of the SVF could be measured in order to retrieve the 3-D SVF without making any assumption. Fig. 20 shows the final 3-D SVF after combining the four measurements of two orthogonal acquisitions.

The monitoring of glaciers is essential to predict their evolution under the threat of climate change, and the highresolution SVF derived with airborne SAR can be used within ice flow models to improve the estimation of the ice thickness of the glacier [84].

\section{Soil Moisture Estimation}

Soil moisture is a key parameter in hydrological modeling that affects a variety of hydrological processes and is recognized as an emerging essential climate variable 
(ECV) by the Intergovernmental Panel on Climate Change (IPCC) [85]. In principle, SAR is known to have the potential to provide such high-resolution soil moisture maps at short time intervals. However, systematic monitoring of soil moisture with a high spatial and temporal resolution is still a big challenge in Earth observation. The advantage of VHR soil moisture mapping with airborne fully polarimetric SAR is that information about the spatial moisture distribution is obtained to enable precision farming with a point-exact irrigation on the intrafield scale as well as to improve the initialization of watershed runoff models and with it also the model prediction of soil moisture. High-resolution soil moisture maps from airborne sensors are also used complementary to lower spatial scale imaging, like from airborne radiometers or as it is operationally performed from the spaceborne Soil Moisture and Ocean Salinity Mission (SMOS) [86].

First soil moisture analyzes were carried out on singlepolarization intensities over bare soils, which led to the illposed problem having both the soil moisture and the soil roughness influence in just one acquired signal [87], [88]. With the emerging establishment of airborne fully polarimetric SAR sensors, the observation space was enlarged by SAR polarimetry to separate the soil roughness from the soil moisture contribution on the signal for an unambiguous retrieval of soil moisture over bare soils [89].

Moreover, the performance of conventional soil moisture inversion algorithms is strongly compromised by the presence of vegetation. Therefore, the fact that agriculture fields are most of the year covered by vegetation makes the development of a distinct approach essential. A promising solution is the use of fully polarimetric SAR at lower frequencies providing an appropriate penetration as well as an observation space that allows the interpretation and decomposition of different scattering contributions. Indeed, polarimetric decomposition techniques have been successfully developed and used to filter the disturbing vegetation contribution, allowing the estimation of moisture content on the isolated surface components [62], [90]. Fig. 21 shows the high-resolution soil moisture maps for different moisture levels, which were obtained from airborne fully polarimetric L-band data acquired by the E-SAR sensor at three different dates. This analysis was conducted within the framework of the agricultural bio/geophysical retrieval from frequent repeatpass SAR and optical imaging (AGRISAR) experiment in 2006. At the time of the first acquisition, the crop layer was still short and sparse. Crop height and density increased with time to the next acquisitions performed almost one and two months later. However, the comparison with the ground measurements indicated that despite the growth of the vegetation cover, soil moisture was estimated with an impressive root mean square error (RMSE) between 4 vol\% and 11 vol\%. (The detailed validation is provided in [91], while only the measured moisture trend is shown on the bottom of Fig. 21.)
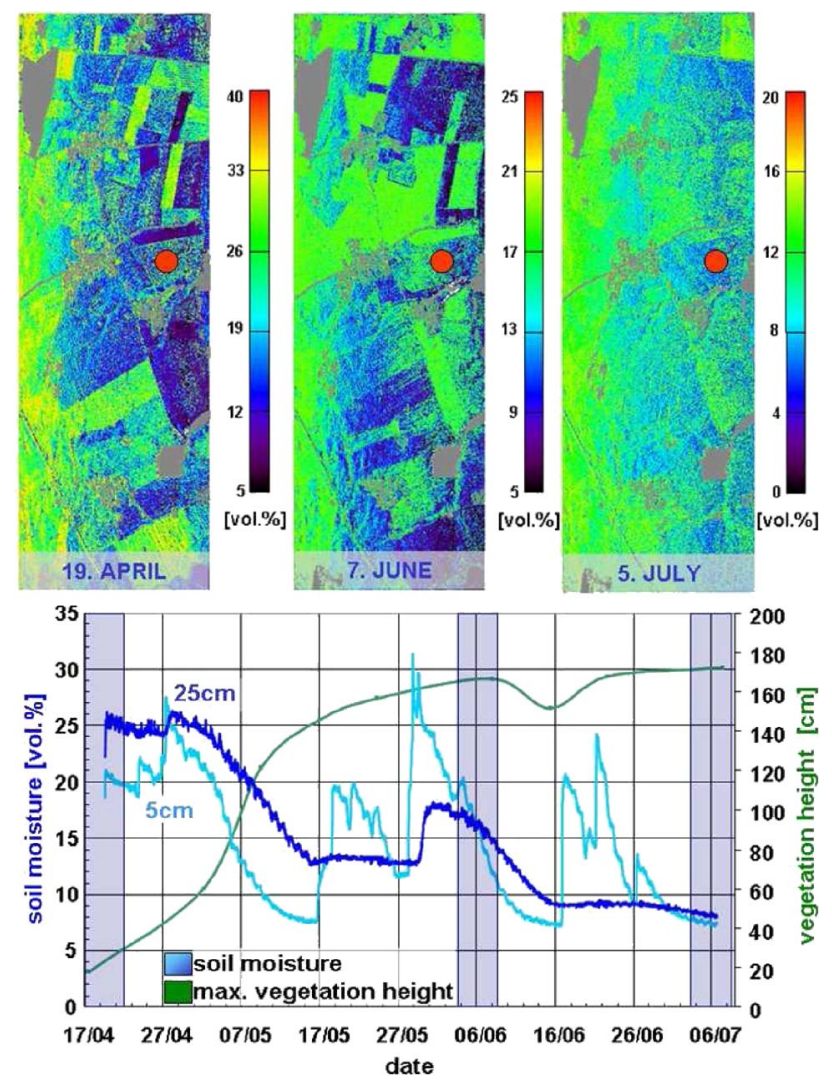

Fig. 21. Top: Soil moisture maps obtained after applying polarimetric decomposition techniques on L-band polarimetric data acquired at three different dates. Bottom: Ground soil moisture measurements versus mean vegetation height performed on the field indicated by the red circle [91]. Dark blue: Soil moisture at 25-cm depth; light blue: at 5-cm depth.

\section{E. Forest Structure/3-D Imaging}

The capability of the radar signal to penetrate volumetric structures (e.g., vegetation) leads to the possibility of retrieving information about their vertical distribution. This section is dedicated to describing two of the most promising techniques having such goal, namely polarimetric SAR interferometry (Pol-InSAR) [92]-[94] and SAR tomography (TomoSAR) [95], [96].

The introduction of Pol-InSAR techniques in the last decade led to a breakthrough in quantitative estimation of key forest structure parameters, such as forest height. In fact, this is one of the most important parameters in forestry and describes, along with basal area and tree species or species composition, dynamic forest development, modeling, and inventory. Forest height is rather hard to be measured on the ground; typical estimation errors are given with 5\%-10\% accuracy, depending on the forest and tree conditions, and increase with forest height and density. Height estimation from polarimetric single-baseline and multibaseline data has been developed and demonstrated through a series of airborne experiments, covering 

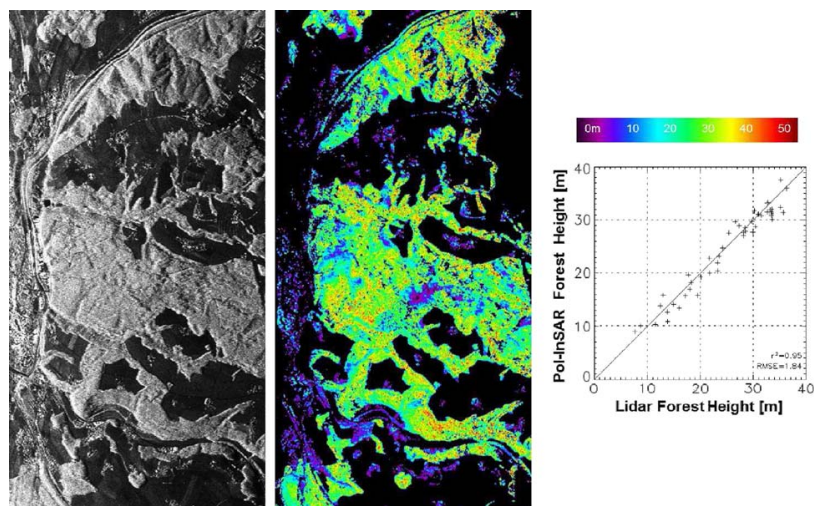

Fig. 22. L-band HV intensity image of the Traunstein test site (left), forest height map computed from Pol-InSAR data and validation plot.

a large variety of forest conditions and types (temperate, boreal, and tropical sites characterized by different stand, terrain, and environmental conditions). The validation against Lidar and/or ground measurements indicates estimation accuracy - widely independent of terrain and/ or forest conditions - in the order of $10 \%$ compared to the forest top height.

An example of state-of-the-art Pol-InSAR forest height products is shown in Fig. 22. On the left, an L-band SAR image of the Traunstein forest site, acquired by the E-SAR and located in southern Germany, is shown. The site is characterized by a large variety of forest stand conditions in the presence of locally variable topography. In the center of Fig. 22, the forest height map derived from PolInSAR data acquired at L-band is shown; on the right, the corresponding validation plot against Lidar measurements is presented.

Forest height maps with a spatial resolution better than $5 \mathrm{~m}$ are required for forest inventory applications in countries with a developed inventory system, as is the case for central and northern Europe, implying sensor resolution on the order of $1 \mathrm{~m}$ and better. A second, and even more important application, that requires forest height maps with high spatial resolution is the detection and quantification of forest disturbance. The ability to detect forest degradation at a high spatial resolution as caused, for example, by selective logging, is critical for the protection of forest environments. Fig. 23 shows a forest height map of the Mawas region in Indonesia, derived from P-band Pol-InSAR data acquired by E-SAR during the Indrex-II campaign in 2004 [45]. In the forested part, tree height ranges between 15 and $27 \mathrm{~m}$. The logging trails caused by logging activities 10-15 years ago are clearly visible as well as the higher degree of disturbances close to the trails.

A direct possibility for resolving the vertical structure of forests and other targets is the formation of a second synthetic aperture in elevation, perpendicular to the flight

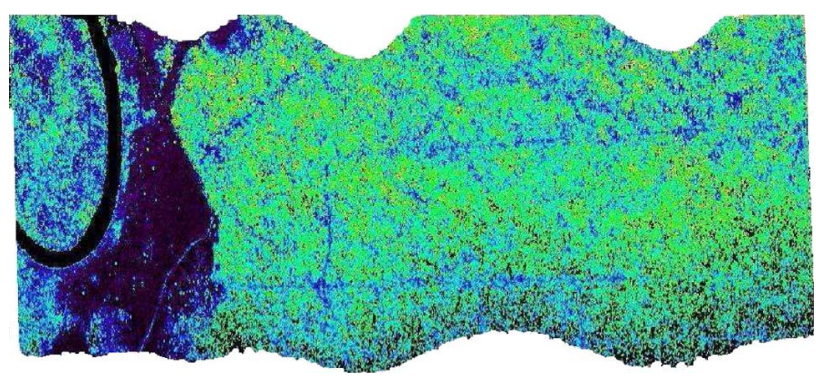

Fig. 23. Forest height map of the Mawas region, Indonesia, derived from Pol-InSAR data acquired during the Indrex-II campaign in 2004.

track. This technique is known as SAR tomography [95], [96] and can be implemented through several parallel tracks with horizontal and/or vertical displacements (Fig. 24). A larger spatial extent of this aperture provides a better vertical resolution (height), while a closer spacing between adjacent tracks enlarges the unambiguous height range (Nyquist criterion). As a result, ideal sampling conditions require a large number of regular passes. However, for the airborne case, the number of images is limited by the platform's capacity for continuous acquisition and typically lies between 5 and 20 .

In practice, after focusing and coregistering a set of SAR images, one can apply beamforming techniques as a function of height so as to retrieve vertical profiles [96]. An example of a linear Fourier reconstruction is depicted in Fig. 25, which represents a tomogram (azimuth-height slice) of a forest.

Alternatively, other approaches can be chosen to overcome the aforementioned sampling requirements. For

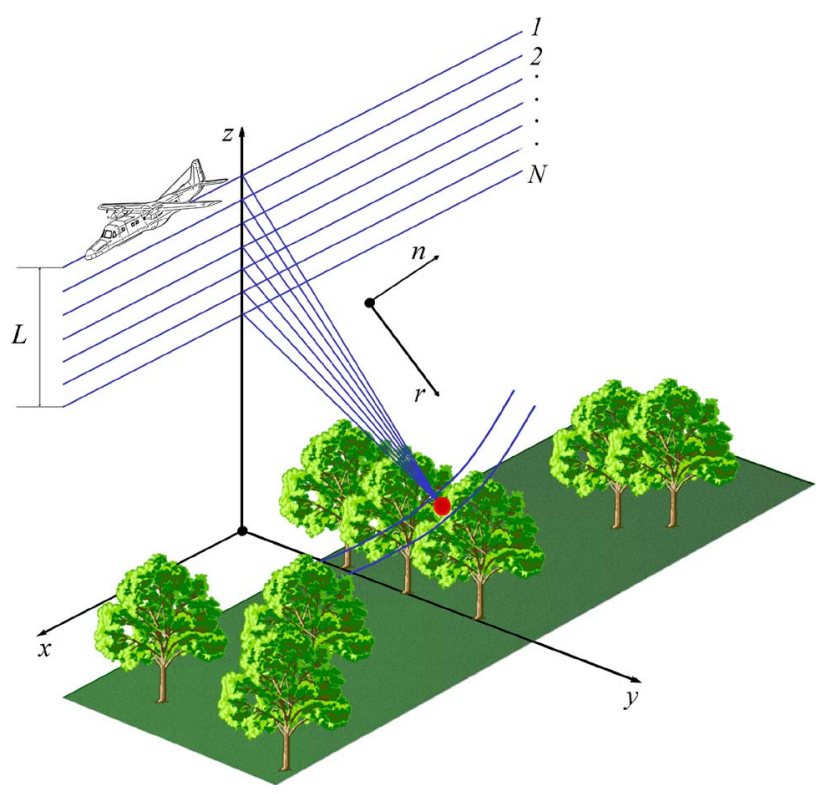

Fig. 24. Tomographic acquisition geometry. 


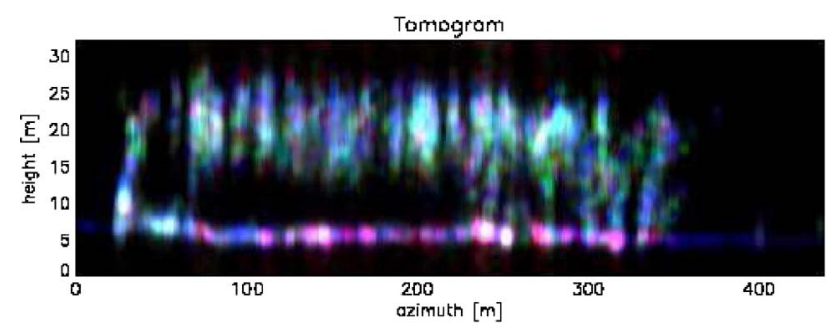

Fig. 25. Polarimetric tomogram of a forest (Pauli basis) obtained with 21 acquisitions. The different colors indicate different scattering contributions: Double-bounce reflections due to the ground-trunk interaction (red), single-bounce reflections can be identified right next to the azimuth coordinate of $\mathbf{3 5 0} \mathbf{m}$ due to the absence of vegetation (blue), and canopy contributions (green).

instance, super-resolution spectral estimators such as Capon, and subspace methods have been employed [97]-[100]. Fig. 26 depicts the Capon tomogram of a target hidden beneath vegetation [98].

Another important result consists of the first controlled tomographic demonstration, where two corner reflectors have been placed in a layover geometry [Fig. 27(a)]. By means of Fourier beamforming, SAR tomography allowed one to tell both scattering centers apart and to retrieve their vertical distance of $3.5 \mathrm{~m}$ as well as their polarimetric signature [Fig. 27(b)].

Last, recent work has concentrated on a robust reduction of the number of acquisitions for both regular [101] and irregular track distributions [98], [102], [103]. In this context, sparsity-driven techniques such as compressed sensing become possible [104], [105]. Fig. 28 presents the two corner reflectors already introduced by Fig. 27(a) relying on only five acquisitions with a distributed compressed sensing approach [106].

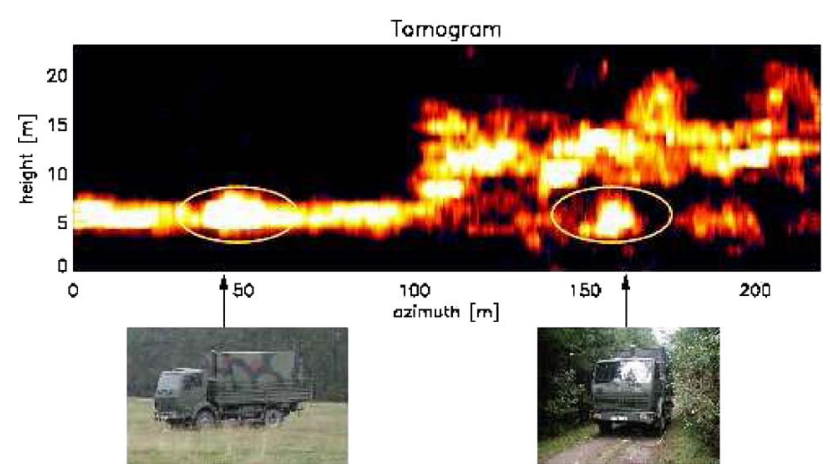

Fig. 26. SAR tomogram of two trucks obtained with 21 acquisitions. One truck is located outside and the other inside the forest. The absence of the ground-trunk double-bounce reflections for azimuth coordinates next to the truck is due to the fact that the truck has been placed on a path parallel to the flight direction (as shown in the bottom right photograph).

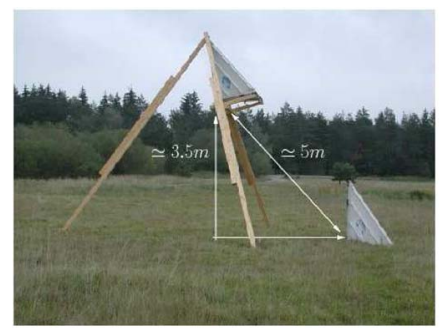

(a)

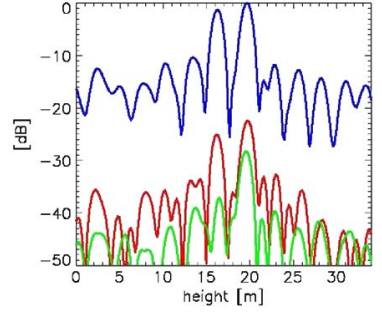

(b)
Fig. 27. (a) Photo of two corner reflectors placed in a layover geometry. (b) Tomographic intensity image representing their location in the three Pauli channels carried out with the Fourier beamformer and 21 acquisitions. The dominant odd-bounce reflection, typical of trihedral corner reflectors, is retrieved (b/ue). The correct height difference of $\mathbf{3 . 5} \mathbf{m}$ is measured. Red: Even bounce; blue: Odd bounce; green: Cross polarized.

\section{F. Traffic Monitoring}

In conventionally processed SAR images, moving vehicles generally appear blurred and displaced from their actual positions [107]. The reason are the different Doppler frequencies with respect to the stationary nonmoving objects. A SAR traffic processor has the objective to detect the moving vehicles and to determine their actual geographic positions, their velocities, and moving directions. For this task, principally ground moving target indication (GMTI) algorithms originated in the military field can be used [108]-[111].

Slowly moving vehicles are embedded in the clutter Doppler spectrum caused by the radar platform motion. For enabling the detection, at least a second receiving antenna displaced in azimuth direction is required. Clutter suppression can then be performed by using the displaced phase center antenna (DPCA) technique [112]. Each antenna observes the scene from the same point in space at

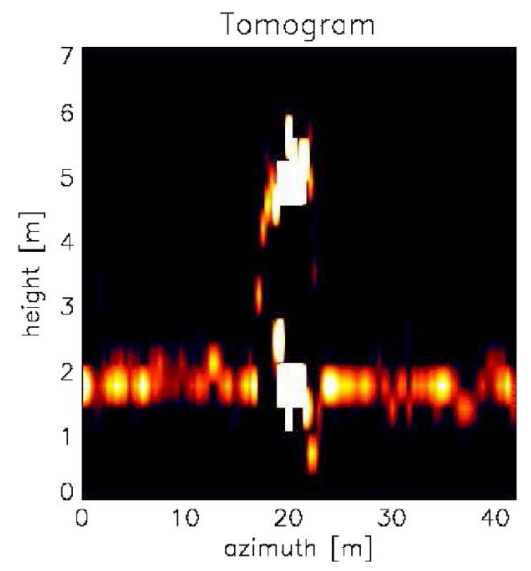

Fig. 28. Tomogram of the two corner reflectors in layover obtained with only five acquisitions and with a distributed compressed sensing approach. 
slightly different times. During this short time lag, the signals from stationary targets remain the same, whereas the signals from vehicles moving in range direction cause a phase shift. By subtracting the signals received by the fore and aft antenna, the clutter is suppressed but the moving target signals remain in the data. If both clutter suppression and accurate parameter estimation are performed, at least a three-channel system will be required [113].

In the multichannel case, the application of space-time adaptive processing (STAP) techniques is more powerful than DPCA [110], [111], [114]-[117]. By incorporating the a priori known road network into the detection stage of the GMTI algorithm and by ignoring vehicles moving on open land (they may be of interest for military applications but not for civilian road traffic monitoring), the system complexity and the computational load can be reduced significantly [118]-[120]. Furthermore, for many traffic monitoring applications, a snapshot of the actual traffic situation is sufficient so that complex and computation time-consuming target tracking (which often can be found in combination with STAP algorithms) is not required.

In [121], a fast traffic monitoring algorithm based on a priori knowledge has been presented. The algorithm operates on range-compressed data so that no time-consuming

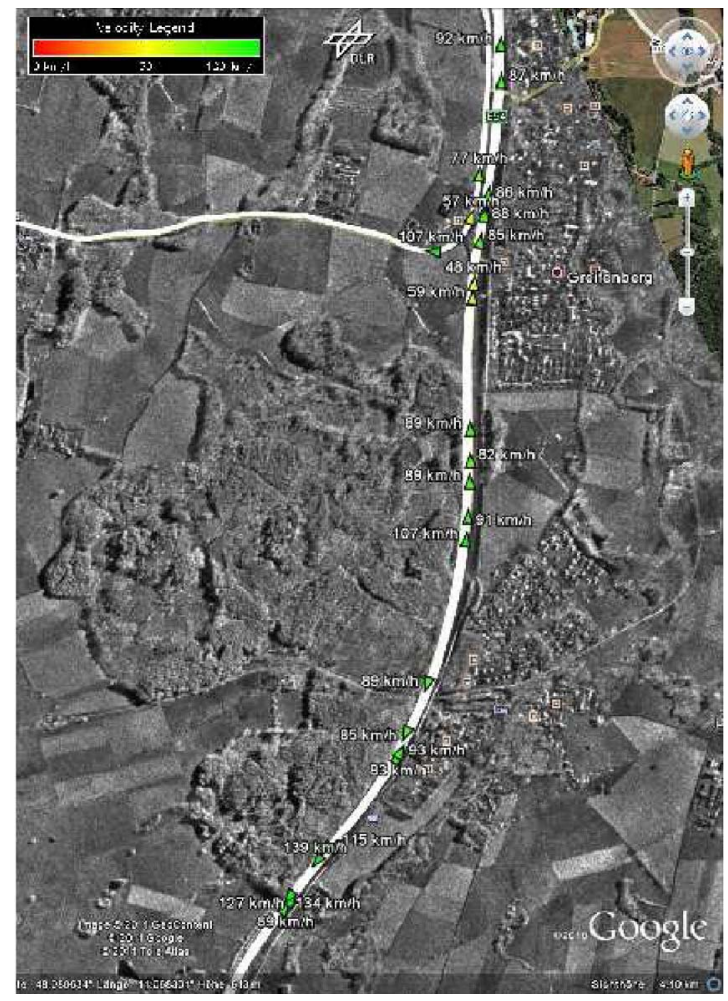

Fig. 29. Output of the traffic processor as Google Earth overlay. The image shows a part of the highway 496 near Ammersee, Bavaria. The color-coded symbols (color is velocity dependent) mark the estimated "true" geographical positions of the automatically detected road vehicles. Dual-channel F-SAR data were used as input.

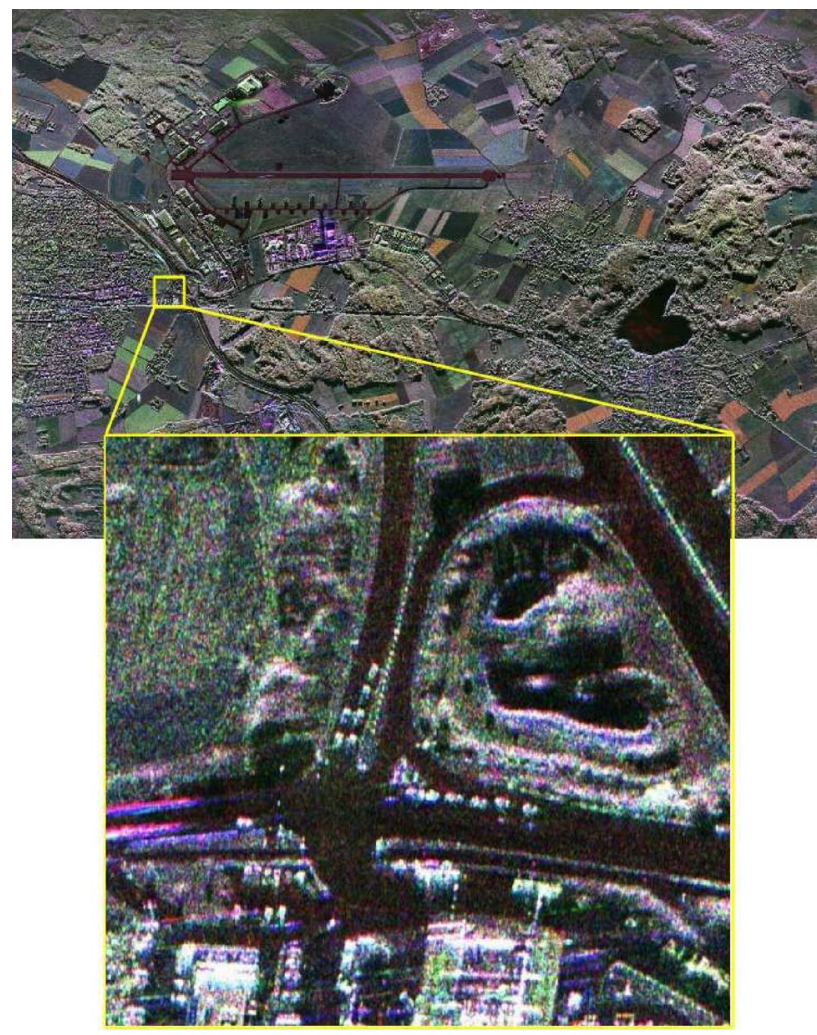

Fig. 30. High-resolution $\left(0.25 \times 0.25 \mathrm{~m}^{2}\right)$ polarimetric $\mathrm{X}$-band image acquired with DLR's F-SAR sensor.

SAR imaging is necessary. The roads obtained from the OpenStreetMap database are directly mapped to corresponding azimuth beam center coordinates in the rangecompressed data array. Only the intersections of the moving vehicle signals with the roads are evaluated. A traffic monitoring result obtained from that traffic processor applied on X-band data acquired with F-SAR is shown in Fig. 29.

Principally for GMTI and traffic monitoring no high resolution is required: lower data rates allow for faster computation and a position accuracy (limited by the range and azimuth resolution) of a few meters often is sufficient. However, high resolution in combination with GMTI allows for the application of inverse SAR (ISAR) imaging techniques [122]. Thus, not only moving vehicles can be detected and their positions, velocities, and moving directions can be estimated, but they also can be refocused with VHR. A further step would then be the application of pattern recognition techniques, so that, for example, a discrimination between motorbikes, passenger cars, and trucks becomes possible. In Fig. 30, a high-resolution SAR image of a junction is shown. The nonmoving passenger cars waiting in front of the traffic lights clearly can be recognized and their dimensions can be estimated. By sophisticated ISAR techniques such sharp images can be generated principally also from moving vehicles [123]. 


\section{SUMMARY AND OUTLOOK}

High-resolution airborne SAR systems are revolutionizing the information extraction in a wide range of remote sensing applications. Examples are environmental remote sensing, road traffic, hazard and disaster monitoring, as well as reconnaissance and security related applications. However, airborne sensors will remain limited to local and/or regional aspects. For global coverage, spaceborne SAR systems become mandatory. In a changing and dynamic world, high-resolution and timely geospatial information with global access and coverage becomes increasingly important. SAR remote sensing will play a major role in this task, since SAR is the only sensor technology that combines all-weather, day-and-night with high-resolution imaging capability.

One challenge for future spaceborne SAR systems is to optimize the performance-to-cost ratio as much as possible so that large-scale imaging with fast repeat intervals becomes possible. An attractive solution could be the usage of a constellation of satellites in the form of small receiver satellites acquiring the backscattered signal of active medium Earth orbit (MEO) or geosynchronous Earth orbit (GEO) satellites. This requires innovative concepts with bistatic and multistatic system configurations. Digital beamforming for transmit and/or receive will solve the contradiction posed by the antenna size in traditional SAR systems that prohibits the SAR sensor from having high azimuth resolution and a large swath width at the same time. Digital beamforming is a clear trend for future systems, allowing enormous flexibility in the sensor imaging mode, sensor calibration, interference removal, and ambiguity suppression. These concepts will allow the implementation of a flexible SAR sensor network with a faster access time and almost continuous imaging capability, which is necessary for time-critical applications. Highflying platforms and unmanned vehicles will certainly act as a complementary platform for this network of sensors. Furthermore, radar satellites flying in close formation will allow the construction of sparse arrays with enhanced imaging capabilities.

Another important aspect for present and future microwave sensors is the ability to provide quantitative and reliable data products to the user community. Today, the sensor information becomes multidimensional as different sensor sources, polarizations, temporal and spatial baselines, aspect angles, and frequencies are used for parameter retrieval.

\section{REFERENCES}

[1] F. T. Ulaby, R. K. Moore, and A. K. Fung, Microwave Remote Sensing, Vol. 1 \& 2. Reading, MA: Addison-Wesley, 1981.

[2] L. C. Graham, "Synthetic interferometric radar for topographic mapping," Proc. IEEE, vol. 62, no. 6, pp. 763-768, Jun. 1974.

[3] R. M. Goldstein, H. A. Zebker, and C. L. Werner, "Satellite radar interferometry: Two-dimensional phase unwrapping," Radio Sci., vol. 23, no. 4, pp. 713-720, Jul. 1988

[4] M. Werner, "Shuttle radar topography mission (SRTM) - Mission overview," in Proc. Eur. Conf. Synthetic Aperture Radar, München, Germany, 2000, pp. 209-212.

[5] G. Krieger, A. Moreira, H. Fiedler, I. Hajnsek, M. Werner, M. Younis, and M. Zink, "TanDEM-X: A satellite formation for high-resolution SAR interferometry," IEEE Trans. Geosci. Remote Sens., vol. 45, no. 11, pt. 1, pp. 3317-3341, Nov. 2007.

[6] A. K. Gabriel, R. M. Goldstein, and H. A. Zebker, "Mapping small elevation changes over large areas: Differential radar interferometry," J. Geophys. Res., vol. 94, pp. 9183-9191, 1989.

[7] D. Massonet, M. Rossi, C. Carmona, F. Adragna, G. Pelzer, K. Feigl, and T. Rabaute, "The displacement field of the Landers earthquake mapped by radar interferometry," Nature, vol. 364, pp. 138-142, 1993.

[8] A. Ferretti, C. Prati, and F. Rocca, "Permanent scatterers in SAR interferometry," IEEE Trans. Geosci. Remote Sens., vol. 39, no. 1, pp. 8-20, Jan. 2001.

[9] R. Kwock and M. A. Fahnestock, "Ice sheet motion and topography from radar interferometry," IEEE Trans. Geosci. Remote Sens., vol. 34, no. 1, pp. 189-220, Jan. 1996.

[10] A. Ferretti, C. Prati, and F. Rocca, "Nonlinear subsidence rate estimation using permanent scatterers in differential SAR interferometry," IEEE Trans. Geosci. Remote Sens., vol. 38, no. 5, pp. 2202-2212, Sep. 2000.

[11] D. Massonet, P. Briole, and A. Arnaud, "Deflation of Mount Etna monitored by spaceborne radar interferometry," Nature, vol. 375, pp. 567-570, 1993.

[12] G. Sinclair, "Modification of the radar range equation for arbitrary targets and arbitrary polarization," Antenna Lab., The Ohio State Univ. Res. Found., Columbus, OH, Rep. 302-19, 1948.

[13] R. Horn, "The DLR airborne SAR project E-SAR," in Proc. Int. Geosci. Remote Sens. Symp., Lincoln, NE, 1996, pp. 1624-1628.

[14] A. L. Gray and P. J. Farris-Manning, "Repeat-pass interferometry with airborne synthetic aperture radar," IEEE Trans. Geosci. Remote Sens., vol. 31, no. 1, pp. 180-191, Jan. 1993.

[15] H. A. Zebker, S. N. Madsen, J. Martin, K. B. Wheeler, T. Miller, Y. Lou, G. Alberti, S. Vetrella, and A. Cucci, "The topSAR interferometric radar topographic mapping instrument," IEEE Trans. Geosci. Remote Sens., vol. 30, no. 5, pp. 933-940, Sep. 1992.

[16] S. R. Cloude and E. Pottier, "An entropy based classification scheme for land applications of polarimetric SAR," IEEE Trans. Geosci. Remote Sens., vol. 35, no. 1, pp. 68-78, Jan. 1997.

[17] J.-S. Lee, M. R. Grunes, and R. Kwok, "Classification of multi-look polarimetric SAR imagery based on the complex Wishart distribution," Int. J. Remote Sens., vol. 15, no. 11, pp. 2299-2311, 1994.

[18] E. Rignot, R. Chellappa, and P. Dubois, "Unsupervised segmentation of polarimetric SAR data using the covariance matrix," IEEE Trans. Geosci. Remote Sens., vol. 30, no. 4, pp. 697-705, Jul. 1992.

[19] S. R. Cloude and E. Pottier, "A review of target decomposition theorems in radar polarimetry," IEEE Trans. Geosci. Remote Sens., vol. 34 , no. 2, pp. 498-518, Mar. 1996.

[20] S. R. Cloude, I. Hajnsek, and K. P. Papathanassiou, "Eigenvector methods for the extraction of surface parameters in polarimetric SAR," in Proc. Comm. Earth Observ. Satell. (CEOS) SAR Workshop, Toulouse, France, 1999, pp. 693-698.

[21] J.-S. Lee, M. R. Grunes, T. L. Ainsworth, L.-J. Du, D. L. Schuler, and S. R. Cloude, "Unsupervised classification using polarimetric decomposition and the complex Wishart classifier," IEEE Trans. Geosci. Remote Sens., vol. 37, no. 5, pp. 2249-2258, Sep. 1999.

[22] E. Pottier and J.-S. Lee, "Unsupervised classification scheme of POLSAR images based on the complex Wishart distribution and the $\mathrm{h} / \mathrm{a} / \alpha$ polarimetric decomposition theorem," in Proc. Eur. Conf. Synthetic Aperture Radar, München, Germany, 2000, pp. 265-268.

[23] S. Hensley, K. Wheeler, G. Sadowy, C. Jones, S. Shaffer, H. Zebker, T. Miller, B. Heavey, E. Chuang, R. Chao, K. Vines, K. Nishimoto, J. Prater, B. Carrico, N. Chamberlain, J. Shimada, M. Simard, B. Chapman, R. Muellerschoen, C. Le, T. Michel, G. Hamilton, D. Robison, G. Neumann, R. Meyer, P. Smith, J. Granger, P. Rosen, D. Flower, and R. Smith, "The UAVSAR instrument: Description and first results," in Proc. IEEE Radar Conf., May 2008, DOI: $10.1109 /$ RADAR.2008.4720722.

[24] E. L. Christensen, N. Skou, J. Dall, K. W. Woelders, J. H. Jorgensen, J. Granholm, and S. N. Madsen, "EMISAR: An absolutely calibrated polarimetric L- and C-band SAR," IEEE Trans. Geosci. Remote Sens., vol. 36, no. 6, pp. 1852-1865, Nov. 1998.

[25] A. Reigber, M. Jager, J. Fischer, R. Horn, R. Scheiber, P. Prats, and A. Nottensteiner, 
System status and calibration of the F-SAR airborne SAR instrument," in Proc. Int. Geosci. Remote Sens. Symp., Vancouver, BC, Canada, 2011, pp. 1520-1523.

[26] M. Rombach and J. Moreira, "Description and applications of the multipolarized dual-band OrbiSAR-1 InSAR sensor," in Proc. Int. Radar Conf., Huntsville, AL, 2003, pp. 245-250.

[27] H. Hellsten, L. M. H. Ulander, A. Gustavsson, and B. Larsson, "Development of VHF CARABAS-II SAR," in Proc. SPIE AeroSense Conf., Orlando, FL, 1996, pp. 48-60.

[28] J. Rippler, "Ultrahigh resolution X-band SAR images with SmartRadar," in Proc. Eur. Conf. Synthetic Aperture Radar, Nuremberg, Germany, 2012, pp. 426-428.

[29] S. Hensley, E. Chapin, A. Freedman, C. Le, S. Madsen, T. Michel, E. Rodriguez, P. Siqueira, and K. Wheeler, "First P-band results using the GeoSAR mapping system," in Proc. Int. Geosci. Remote Sens. Symp., Sydney, Australia, 2001, pp. 126-128.

[30] M. E. Bullock, G. Lawrence, R. V. Dams, and K. Tennant, "Map generation utilizing IFSAR imagery and digital elevation models from the intermap STAR-3i system," in Proc. Int. Geosci. Remote Sens. Symp., Singapore, 1997, pp. 1350-1357.

[31] J. R. Moreira, "Aes-1: Ein hochauflösendes interferometrisches SAR-system zur abbildung und geländemodellgenerierung," in Proc. DGON Radar Conf., Stuttgart, Germany, 1997, pp. 353-363.

[32] S. Uratsuka, M. Satake, T. Kobayashi, T. Umehara, A. Nadai, H. Maeno, H. Masuko, and M. Shimada, "High-resolution dual-band interferometric and polarimetric SAR (PI-SAR) and its applications," in Proc. Int. Geosci. Remote Sens. Symp., Toronto, ON, Canada, 2002, pp. 1720-1722.

[33] T. Matsuoka, T. Umehara, A. Nadai, T. Kobayashi, M. Satake, and S. Uratsuka, "Calibration of the high performance airborne SAR system Pi-SAR2," in Proc. Int. Geosci. Remote Sens. Symp., 2009, vol. 4, pp. 582-585.

[34] J. H. G. Ender and A. R. Brenner, "PAMIR - A wideband phased array SAR/MTI system," in Proc. Eur. Conf. Synthetic Aperture Radar, Köln, Germany, 2002, pp. 157-162.

[35] B. Pairault and M. Berthod, "RAMSES interferometer: Toward high resolution 3D SAR," in Proc. Eur. Conf. Synthetic Aperture Radar, Friedrichshafen, Germany, 1998, pp. 87-90.

[36] O. R. du Plessis, J. F. Nouvel, R. Baque, G. Bonin, P. Dreuillet, C. Coulombieux, and H. Oriot, "ONERA SAR facilities," IEEE Aerosp. Electron. Syst. Mag., vol. 26, no. 11, pp. 24-30, Nov. 2011.

[37] L. M. H. Ulander, H. Hellsten, and G. Stenstrom, "Synthetic-aperture radar processing using fast factorized back-projection," IEEE Trans. Aerosp. Electron. Syst., vol. 39, no. 3, pp. 760-776, Jul. 2003.

[38] M. Rodriguez-Cassola, P. Prats, G. Krieger, and A. Moreira, "Efficient time-domain image formation with precise topography accommodation for general bistatic SAR configurations," IEEE Trans. Aerosp. Electron. Syst., vol. 47, no. 4, pp. 2949-2966, Oct. 2011.

[39] I. G. Cumming and F. H. Wong, Digital Processing of Synthetic Aperture Radar
Data. Algorithms and Implementation. Boston, MA: Artech House, 2005.

[40] C. Cafforio, C. Prati, and F. Rocca, "SAR data focusing using seismic migration techniques," IEEE Trans. Aerosp. Electron. Syst., vol. 27, no. 2, pp. 194-207, Mar. 1991.

[41] R. K. Raney, H. Runge, R. Bamler, I. Cumming, and F. Wong, "Precision SAR processing using chirp scaling," IEEE Trans. Geosci. Remote Sens., vol. 32, no. 4, pp. 786-799, Jul. 1994.

[42] A. Moreira and Y. Huang, "Airborne SAR processing of high squinted data using a chirp scaling approach with integrated motion compensation," IEEE Trans. Geosci. Remote Sens., vol. 32, no. 5, pp. 1029-1040, Sep. 1994.

[43] A. Moreira, J. Mittermayer, and R. Scheiber, "Extended chirp scaling algorithm for air- and spaceborne SAR data processing in Stripmap and ScanSAR imaging modes," IEEE Trans. Geosci. Remote Sens., vol. 34, no. 5, pp. 1123-1136, Sep. 1996.

[44] A. Reigber, E. Alivizatos, A. Potsis, and A. Moreira, "Extended wavenumber domain SAR focusing with integrated motion compensation," Inst. Electr. Eng. Proc.-Radar Sonar Navig., vol. 153, no. 3, pp. 301-310, 2006.

[45] I. Hajnsek, F. Kugler, S. Lee, and K. Papathanassiou, "Tropical forest parameter estimation by means of POL-INSAR: The INDREX-II campaign," IEEE Trans. Geosci. Remote Sens., vol. 47, no. 2, pp. 481-493, Feb. 2009.

[46] R. Scheiber, "A three-step phase correction approach for airborne repeat-pass interferometric SAR data," in Proc. Int. Geosci. Remote Sens. Symp., Toulouse, France, 2003, pp. 1190-1992.

[47] K. A. C. de Macedo and R. Scheiber, "Precise topography- and aperture-dependent motion compensation for airborne SAR," IEEE Geosci. Remote Sens. Lett., vol. 2, no. 2 , pp. 172-176, Apr. 2005.

[48] P. Prats, A. Reigber, and J. J. Mallorqui, "Topography-dependent motion compensation for repeat-pass SAR systems," IEEE Geosci. Remote Sens. Lett., vol. 2, no. 2, pp. 206-210, Apr. 2005.

[49] P. Prats, K. A. Macedo, A. Reigber, R. Scheiber, and J. J. Mallorqui, "Comparison of topography and aperture dependent motion compensation algorithms for airborne SAR," IEEE Geosci. Remote Sens. Lett., vol. 4, no. 3, pp. 349-353, Jul. 2007.

[50] P. Prats and J. J. Mallorqui, "Estimation of azimuth phase undulations with multisquint processing in airborne interferometric SAR images," IEEE Trans. Geosci. Remote Sens., vol. 41, no. 6, pp. 1530-1533, Jun. 2003.

[51] A. Reigber, P. Prats, and J. J. Mallorqui, "Refined estimation of time-varying baseline errors in airborne SAR interferometry," IEEE Geosci. Remote Sens. Lett., vol. 3, no. 1, pp. 145-149, Jan. 2006.

[52] R. Scheiber and A. Moreira, "Coregistration of interferometric SAR images using spectral diversity," IEEE Trans. Geosci. Remote Sens., vol. 38, no. 5, pp. 2179-2191, Sep. 2000.

[53] E. Erten, A. Reigber, and O. Hellwich, "Generation of three-dimensional deformation maps from INSAR data using spectral diversity techniques," ISPRS J. Photogramm. Remote Sens., vol. 65, no. 4, pp. 388-394, Jul. 2010.

[54] N. B. D. Bechor and H. A. Zebker, "Measuring two-dimensional movements using a single InSAR pair," Geophys. Res. Lett., vol. 33, L16311, 2006.

[55] P. Prats, R. Scheiber, A. Reigber, C. Andres, and R. Horn, "Estimation of the surface velocity field of the Aletsch glacier using multibaseline airborne SAR interferometry," IEEE Trans. Geosci. Remote Sens., vol. 47, no. 2, pp. 419-430, Feb. 2009.

[56] K. A. C. de Macedo, R. Scheiber, and A. Moreira, "An autofocus approach for residual motion errors with application to airborne repeat-pass SAR interferometry," IEEE Trans. Geosci. Remote Sens., vol. 46, no. 10, pp. 3151-3162, Oct. 2008.

[57] W. Pitz and D. Miller, "The TerraSAR-X satellite," IEEE Trans. Geosci. Remote Sens., vol. 48, no. 2, pp. 615-622, Feb. 2010.

[58] L. M. H. Ulander, P. O. Frölind, and T. Martin, "Processing and calibration of ultra-wideband SAR data from CARABAS-II," in Proc. Comm. Earth Observ. Satell. (CEOS) SAR Workshop, Toulouse, France, Oct. 1999, pp. 273-278.

[59] M. Bachmann, M. Schwerdt, and B. Brautigam, "TerraSAR-X antenna calibration and monitoring based on a precise antenna model," IEEE Trans. Geosci. Remote Sens., vol. 48, no. 2, pp. 690-701, Feb. 2010.

[60] M. Limbach, B. Gabler, R. Horn, and A. Reigber, "DLR-HR compact test range facility," in Proc. 3rd Eur. Conf. Antennas Propag., Mar. 2009, pp. 2186-2189.

[61] M. Jäger, A. Reigber, and R. Scheiber, "Accurate consideration of sensor parameters in the calibration and focusing of F-SAR data," in Proc. Eur. Conf. Synthetic Aperture Radar, Nürnberg, Germany, Apr. 2012, pp. 20-23.

[62] I. Hajnsek, T. Jagdhuber, H. Schön, and K. Papathanassiou, "Potential of estimating soil moisture under vegetation cover by means of PolSAR," IEEE Trans. Geosci. Remote Sens., vol. 47 , no. 2, pp. 442-454, Feb. 2008.

[63] A. Freeman, "SAR calibration: An overview," IEEE Trans. Geosci. Remote Sens., vol. 30, no. 6, pp. 1107-1121, Nov. 1992.

[64] Y. K. Chan and V. C. Koo, "An introduction to synthetic aperture radar (SAR)," Progr. Electromagn. Res. B, vol. 2, pp. 27-60, 2008.

[65] K. Conradsen, A. A. Nielsen, J. Schou, and H. Skriver, "A test statistic in the complex Wishart distribution and its application to change detection in polarimetric SAR data," IEEE Trans. Geosci. Remote Sens., vol. 41, no. 1, pp. 4-19, Jan. 2003.

[66] R. F. Hanssen, Radar Interferometry. Data Interpretation and Error Analysis. Amsterdam, The Netherlands: Kluwer, 2001.

[67] O. Mora, J. J. Mallorqui, and A. Broquetas, "Linear and nonlinear terrain deformation maps from a reduced set of interferometric SAR images," IEEE Trans. Geosci. Remote Sens., vol. 41, no. 10, pp. 2243-2253, Oct. 2003.

[68] P. Berardino, G. Fornaro, R. Lanari, and E. Sansosti, "A new algorithm for surface deformation monitoring based on small baseline differential SAR interferograms," IEEE Trans. Geosci. Remote Sens., vol. 40, no. 11, pp. 2375-2383, Nov. 2002.

[69] R. Lanari, O. Mora, M. Manunta, J. J. Mallorqui, P. Berardino, and E. Sansosti, "A small-baseline approach for investigating deformations on full-resolution differential SAR interferograms," IEEE Trans. Geosci. Remote Sens., vol. 42, no. 7, pp. 1377-1386, Jul. 2004. 
[70] A. Ferretti, G. Savio, R. Barzaghi, A. Borghi, S. Musazzi, F. Novali, C. Prati, and F. Rocca, "Submillimeter accuracy of InSAR time series: Experimental validation," IEEE Trans. Geosci. Remote Sens., vol. 45, no. 5, pp. 1142-1153, May 2007.

[71] A. Reigber, A. Potsis, E. Alivizatos, N. Uzunoglu, and A. Moreira, "Wavenumber domain SARfocusing with integrated motion compensation," in Proc. Int. Geosci. Remote Sens. Symp., Toulouse, France, 2003, pp. 1465-1467.

[72] H. A. Zebker, P. A. Rosen, M. Goldstein, A. K. Gabriel, and C. L. Werner, "On the derivation of coseismic displacement fields using differential radar interferometry," J. Geophys. Res., vol. 99, pp. 19617-19634, 1994.

[73] K. A. C. de Macedo and R. Scheiber, "Controlled experiment for analysis of airborne DInSAR feasibility," in Proc. Eur. Conf. Synthetic Aperture Radar, Ulm, Germany, May 25-29, 2004, pp. 761-764.

[74] J. Groot, "River dike deformation measurement with airborne SAR," IEEE Geosci. Remote Sens. Lett., vol. 1, no. 2 , pp. 94-97, Apr. 2004.

[75] S. Perna, C. Wimmer, J. Moreira, and G. Fornaro, "X-band airborne differential interferometry: Results of the OrbiSAR campaign over the Perugia area," IEEE Trans. Geosci. Remote Sens., vol. 46, no. 2 , pp. 489-503, Feb. 2008.

[76] P. Prats, A. Reigber, J. J. Mallorqui, R. Scheiber, and A. Moreira, "Estimation of the temporal evolution of the deformation using airborne differential SAR interferometry," IEEE Trans. Geosci. Remote Sens., vol. 46, no. 4, pp. 1065-1078, Apr. 2008.

[77] R. M. Goldstein, H. Engelhardt, B. Kamb, and R. M. Frolich, "Satellite radar interferometry for monitoring ice sheet motion: Application to an antarctic ice stream," Science, vol. 262, pp. 1525-1530, 1993.

[78] R. Kwok and M. A. Fahnestock, "Ice sheet motion and topography from radar interferometry," IEEE Trans. Geosci. Remote Sens., vol. 34, no. 1, pp. 189-220, Jan. 1996

[79] I. R. Joughin, R. Kwok, and M. A. Fahnestock, "Interferometric estimation of three-dimensional ice-flow using ascending and descending passes," IEEE Trans. Geosci. Remote Sens., vol. 36, no. 1, pp. 25-37, Jan. 1998.

[80] T. Strozzi, A. Luckman, T. Murray, U. Wegmüller, and C. L. Werner, "Glacier motion estimation using SAR offset-tracking procedures," IEEE Trans. Geosci. Remote Sens., vol. 40, no. 11, pp. 2384-2391, Nov. 2002.

[81] E. Trouvé, G. Vasile, M. Gay, L. Bombrun, P. Grussenmeyer, T. Landes, J.-M. Nicolas, P. Bolon, I. Petillot, A. Julea, L. Valet, J. Chanussot, and M. Koehl, "Combining airborne photographs and spaceborne SAR data to monitor temperate glaciers: Potentials and limits," IEEE Trans. Geosci. Remote Sens., vol. 45, no. 4, pp. 905-924, Apr. 2007.

[82] E. Erten, A. Reigber, and O. Hellwich, "Generation of three-dimensional deformation map at low resolution using a combination of spectral diversity via least square approach," in Proc. ENVISAT Symp., Montreux, Switzerland, Apr. 23-27, 2007 [CD-ROM].

[83] R. Bamler and M. Eineder, "Accuracy of differential shift estimation by correlation and split-bandwidth interferometry for wideband and Delta-k SAR systems," IEEE Geosci. Remote Sens. Lett., vol. 2, no. 2, pp. 151-155, Apr. 2005.

[84] M. Lüthi and M. Funk, "Dating ice cores from a high alpine glacier with a flow model for cold firn," Ann. Glaciol., vol. 31, pp. 69-79, Jan. 2000.

[85] B. C. Bates, Z. W. Kundzewicz, S. Wu, and J. P. Palutikof, "Climate change and water," Intergovernmental Panel on Climate Change, IPCC Secretariat, Geneva, Switzerland, Tech. Rep., 2008.

[86] Y. Kerr, P. Waldteufel, J.-P. Wigneron, J.-M. Martinuzzi, J. Font, and M. Berger, "Soil moisture retrieval from space: The soil moisture and ocean salinity (SMOS) mission," IEEE Trans. Geosci. Remote Sens., vol. 39, no. 8, pp. 1729-1735, Aug. 2001.

[87] R. Bernard, P. Martin, J. L. Thony, M. Vauclin, and D. Vidal-Madjar, "C-band radar for determining surface soil moisture," Remote Sens. Environ., vol. 12, pp. 189-200, 1982.

[88] N. E. C. Verhoest, H. Lievens, W. Wagner, J. Alvarez-Mozos, M. S. Moran, and F. Mattia, "On the soil roughness parameterization problem in soil moisture retrieval of bare surfaces from synthetic aperture radar," Sensors, vol. 8, pp. 4213-4248, 2008.

[89] I. Hajnsek, E. Pottier, and S. R. Cloude, "Inversion of surface parameters from polarimetric SAR," IEEE Trans. Geosci. Remote Sens., vol. 41, no. 4, pp. 727-744, Apr. 2003.

[90] T. Jagdhuber, I. Hajnsek, A. Bronstert, and K. Papathanassiou, "Soil moisture estimation under low vegetation cover using a multi-angular polarimetric decomposition," IEEE Trans. Geosci. Remote Sens., 2012, DOI: 10.1109/TGRS.2012.2209433.

[91] T. Jagdhuber, I. Hajnsek, K. P. Papathanassiou, and A. Bronstert, "Soil moisture retrieval under agricultural vegetation using fully polarimetric SAR," in Proc. Int. Geosci. Remote Sens. Symp., Munich, Germany, 2012, DOI: 10.1109/IGARSS. 2009.5417748.

[92] S. R. Cloude and K. P. Papathanassiou, "Polarimetric SAR interferometry," IEEE Trans. Geosci. Remote Sens., vol. 36, no. 5, pp. 1551-1565, Sep. 1998.

[93] K. P. Papathanassiou and S. R. Cloude, "Single-baseline polarimetric SAR interferometry," IEEE Trans. Geosci. Remote Sens., vol. 39, no. 11, pp. 2352-2361, Nov. 2001.

[94] S. R. Cloude and K. P. Papathanassiou, "Three-stage inversion process for polarimetric SAR interferomtry," Inst. Electr. Eng. Proc.-Radar Sonar Navig., vol. 150, no. 3, pp. 125-134, 2003.

[95] J. Homer, I. D. Longstaff, and G. Callaghan, "High resolution 3D SAR via multi-baseline interferometry," in Proc. IEEE Int. Geosci. Remote Sens. Symp., 1996, vol. 1, pp. 796-798.

[96] A. Reigber and A. Moreira, "First demonstration of airborne SAR tomography using multibaseline L-band data," IEEE Trans. Geosci. Remote Sens., vol. 38, no. 5, pt. 1, pp. 2142-2152, Sep. 2000.

[97] F. Lombardini and A. Reigber, "Adaptive spectral estimation for multibaseline SAR tomography with airborne L-band data," in Proc. IEEE Int. Geosci. Remote Sens. Symp., 2003, vol. 3, pp. 2014-2016.

[98] M. Nannini, R. Scheiber, R. Horn, and A. Moreira, "First 3D reconstructions of targets hidden beneath foliage by means of polarimetric SAR tomography," IEEE Geosci. Remote Sens. Lett., vol. 9, no. 1, pp. 60-64, Jan. 2012.

[99] S. Guillaso and A. Reigber, "Polarimetric SAR tomography," in Proc. PolInSAR, 2005 [CD-ROM].

[100] Y. Huang, L. Ferro-Famil, and A. Reigber, "Under foliage object imaging using SAR tomography and polarimetric spectral estimators," IEEE Trans. Geosci. Remote Sens. vol. 50, no. 6, pp. 2213-2225, Jun. 2012.

[101] M. Nannini, R. Scheiber, and A. Moreira, "Estimation of the minimum number of tracks for SAR tomography," IEEE Trans. Geosci. Remote Sens., vol. 47, no. 2, pp. 531-543, Feb. 2009.

[102] M. Nannini, A. Reigber, and R. Scheiber, "A study on irregular baseline constellations in SAR tomography," in Proc. 8th Eur. Conf. Synthetic Aperture Radar, 2010, pp. 1-4.

[103] V. Severino, M. Nannini, A. Reigber, R. Scheiber, A. Capozzoli, G. D’Elia, A. Liseno, and P. Vinetti, "An approach to SAR tomography with limited number of tracks," in Proc. IEEE Int. Geosci. Remote Sens. Symp., 2009, vol. 4, pp. 216-219.

[104] X. X. Zhu and R. Bamler, "Tomographic SAR inversion by L1-norm regularization-The compressive sensing approach," IEEE Trans. Geosci. Remote Sens., vol. 48, no. 10, pp. 3839-3846, Oct. 2010.

[105] X. X. Zhu and R. Bamler, "Super-resolution power and robustness of compressive sensing for spectral estimation with application to spaceborne tomographic SAR," IEEE Trans. Geosci. Remote Sens., vol. 50, no. 1, pp. 247-258, Jan. 2012.

[106] E. Aguilera, M. Nannini, and A. Reigber, "Multisignal compressed sensing for polarimetric SAR tomography," IEEE Geosci. Remote Sens. Lett., vol. 9, no. 5, pp. 871-875, Sep. 2012.

[107] R. Keith Raney, "Synthetic aperture imaging radar and moving targets," IEEE Trans. Aerosp. Electron. Syst., vol. AES-7, no. 3 , pp. 499-505, May 1971.

[108] J. H. G. Ender, "The airborne experimental multi-channel SAR system AER-II," in Proc. 1st Eur. Conf. Synthetic Aperture Radar, Königswinter, Germany, Mar. 1996, pp. 49-52.

[109] R. Klemm, Space-Time Adaptive Processing: Principles and Applications. London, U.K.: Institute of Electrical Engineers, 1998.

[110] J. H. G. Ender, "Space-time processing for multichannel synthetic aperture radar," Electron. Commun. Eng. J., vol. 11, pp. 29-38, Feb. 1999.

[111] P. Lombardo, F. Colone, and D. Pastina, "Monitoring and surveillance potentialities obtained by splitting the antenna of the COSMO-SkyMed SAR into multiple sub-apertures," Inst. Electr. Eng. Proc.--Radar Sonar Navig., vol. 153, no. 2, pp. 104-116, Apr. 2006.

[112] F. R. Dickey and M. M. Sante, "Final report on anti-clutter techniques," Heavy Military Electron. Dept., General Electric Co., Syracuse, NY, 1953.

[113] J. H. G. Ender, C. H. Gierull, and D. Cerutti-Maori, "Improved space-based moving target indication via alternate transmission and receiver switching," IEEE Trans. Geosci. Remote Sens., vol. 46, no. 12, pp. 3960-3974, Dec. 2008.

[114] D. Cerutti-Maori and I. Sikaneta, "Optimum GMTI processing for space-based SAR/GMTI Systems-Theoretical Deviation," in Proc. 
This article has been accepted for inclusion in a future issue of this journal. Content is final as presented, with the exception of pagination.

Reigber et al.: Very-High-Resolution Airborne Synthetic Aperture Radar Imaging

Eur. Conf. Synthetic Aperture Radar, Aachen, Germany, Jun. 2010, pp. 1-4.

[115] D. Cerutti-Maori and I. Sikaneta, "Optimum GMTI processing for space-based SAR/GMTI systems-Simulation results," in Proc. Eur. Conf. Synthetic Aperture Radar, Aachen, Germany, Jun. 2010, pp. 1-4.

[116] S. Chiu, C. H. Gierull, and A. Durak, "Clutter effects on ground moving targets' interferometric phase," in Proc. IEEE Geosci. Remote Sens. Symp., Seoul, Korea, Jul. 2005, vol. 4, pp. 2928-2931.

[117] D. Cerutti-Maori, J. Klare, A. R. Brenner, and J. G. H. Ender, "Wide area traffic monitoring with the SAR/GMTI System PAMIR," IEEE Trans. Gesci. Remote Sens., vol. 46, no. 10, pp. 3019-3030, Oct. 2008.
[118] F. Meyer, S. Hinz, A. Laika, D. Weihing, and R. Bamler, "Performance analysis of the TerraSAR-X traffic monitoring concept," ISPRS J. Photogramm. Remote Sens., vol. 61, no. 3-4, pp. 225-242, 2006.

[119] S. V. Baumgartner and G. Krieger, "Real-time road traffic monitoring using a fast a priori knowledge based SAR-GMTI algorithm," in Proc. IEEE Int. Geosci. Remote Sens. Symp., Honolulu, HI, Jul. 2010, pp. 1843-1846.

[120] S. Suchandt, H. Runge, H. Breit, U. Steinbrecher, A. Kotenkov, and U. Balss, "Automatic extraction of traffic flows using TerraSAR-X along-track interferometry," IEEE Trans. Geosci. Remote Sens., vol. 48, no. 2, pp. 807-819, Feb. 2010.
[121] S. V. Baumgartner and G. Krieger, "Fast GMTI algorithm for traffic monitoring based on a priori knowledge," IEEE Trans. Geosci. Remote Sens., 2012, DOI: 10.1109/TGRS. 2012.2193133.

[122] V. C. Chen and H. Ling, Time-Frequency Transforms for Radar Imaging and Signal Analysis. Reading, MA: Artech House, 2002.

[123] P. Berens, U. Gebhardt, and J. Holzner, "ISAR imaging of ground moving vehicles using PAMIR data," in Proc. Int. Radar Conf., Surveillance for a Safer World (RADAR), Bordeaux, France, Oct. 2009, pp. 1-5.

\section{ABOUT THE AUTHORS}

Andreas Reigber (Senior Member, IEEE) was born in Munich, Germany, in 1970. He received the diploma degree in physics from the University of Constance, Germany, in 1997, the Ph.D. degree from the University of Stuttgart, Stuttgart, Germany, in 2001, and the habilitation from the Berlin University of Technology, Berlin, Germany, in 2008.

From 1996 to 2000, he was with the Microwave and Radar Institute of the German Aerospace

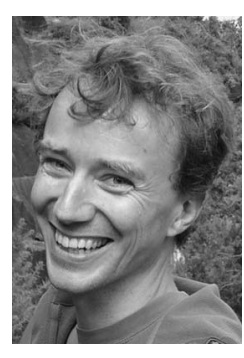
Center (DLR), Wessling, Germany, working in the field of polarimetric SAR tomography. In 2001, he joined the Antenna, Radar and Telecom laboratories of the University of Rennes 1, Rennes, France, for a postdoc on radar polarimetry and polarimetric interferometry. From 2002 to 2007, he was a Research Associate at the Computer Vision and Remote Sensing laboratories of the Berlin University of Technology. Since 2008 , he has been back at the DLR Microwave and Radar Institute, where he is now the Head of the SAR technology department and directing the airborne SAR activities of the institute. His current main research interests are the various aspects of multimodal SAR, like SAR interferometry, SAR polarimetry, SAR tomography, and time-frequency analyses, as well as filtering and classification aspects of high-resolution SAR data.

Dr. Reigber received the EUSAR 2000 Student Prize Paper Award for an article on SAR remote sensing of forests, the IEEE Transactions on Geoscience and Remote Sensing Prize Paper Award in 2001 for a work on polarimetric SAR tomography as well as the IEEE Geoscience and Remote Sensing Letters Prize Paper Award in 2006 for a work on multipass SAR processing.

Rolf Scheiber received the Diploma degree in electrical engineering from the Technical University of Munich, Munich, Germany in 1994 and the Ph.D. degree in electrical engineering from the University of Karlsruhe, Karlsruhe, Germany, in 2003, with a dissertation on airborne SAR interferometry.

Since 1994, he has been with the Microwaves and Radar Institute, German Aerospace Center (DLR), Wessling, Germany, where he developed the operational high-precision interferometric

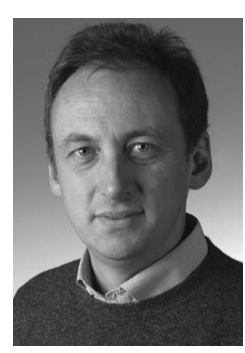
SAR processor for its E-SAR airborne sensor. Since 2001, he has been heading the SAR Signal Processing Group within the SAR Technology Department. His research interests include algorithm development for high-resolution airborne and spaceborne SAR focusing, SAR interferometry, differential SAR interferometry, SAR tomography as well as radio sounding algorithms and applications.

Dr. Scheiber was awarded, as co-author, the 1996 IEEE Transactions on Geoscience and Remote Sensing Prize Paper Award for the contribution "Extended chirp scaling algorithm for air- and spaceborne SAR data processing in Stripmap and ScanSAR imaging modes."
Marc Jäger was born in Karlsruhe, Germany, in 1979. He received the B.A. (honors) degree in computer science from the University of Cambridge, Cambridge, U.K., in 2001 and the M.Sc. degree (with distinction) in digital signal and image processing from DeMontfort University, Leicester, U.K., in 2003.

Currently, he works at the Germal Aerospace Center (DLR), primarily on the polarimetric and interferometric processing of airborne SAR data. His research toward the Ph.D. degree concerns the

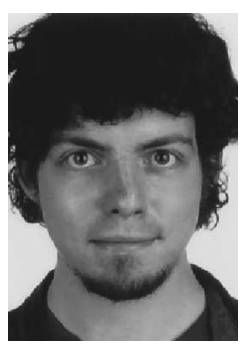
automatic extraction of semantic information from polarimetric and polarimetric interferometric SAR data. His research interests include the unsupervised classification and hierarchical segmentation of SAR data, anisotropic diffusion, and graphical models for inference in object recognition problems.

Mr. Jäger received a Student Paper Award at the Sixth European Conference on Synthetic Aperture Radar (EUSAR 2006).

Pau Prats-Iraola (Member, IEEE) was born in Madrid, Spain, in 1977. He received the Ingeniero degree in telecommunication engineering and the Ph.D. degree from the Universitat Politècnica de Catalunya (UPC), Barcelona, Spain, in 2001 and 2006, respectively.

In 2001, he was a Research Assistant at the Institute of Geomatics, Spain. In 2002, he was at the Department of Signal Theory and Communications, UPC, where he worked in the field of

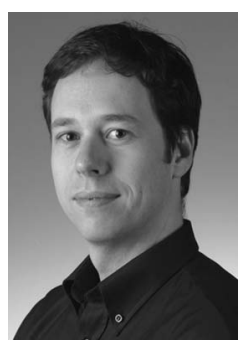
airborne repeat-pass interferometry and airborne differential SAR interferometry. From December 2002 to August 2006, he was an Assistant Professor at the Department of Telecommunications and Systems Engineering, Universitat AutEFnoma de Barcelona, Barcelona, Spain. In 2006, he joined the Microwaves and Radar Institute, German Aerospace Center (DLR), Wessling, Germany, where, since 2009, he has been the Head of the Multimodal Algorithms Group. His research interests include airborne and spaceborne high-resolution SAR processing, SAR interferometry, differential SAR interferometry, and motion compensation for airborne systems.

Dr. Prats-Iraola was the recipient of the first prize of the Student Paper Competition of the 2005 IEEE International Geoscience and Remote Sensing Symposium, Seoul, Korea. 
Irena Hajnsek (Senior Member, IEEE) received the Dipl. degree (honors) from the Free University of Berlin, Berlin, Germany, in 1996 and the Dr. degree (honors) from the Friedrich Schiller University of Jena, Jena, Germany, in 2001.

Since November 2009, she has been a Professor of Earth Observation at the ETH Zürich Institute of Environmental Engineering, Swiss Federal Institute of Technology, Zürich, Switzerland and at the same time the Head of the Polarimetric

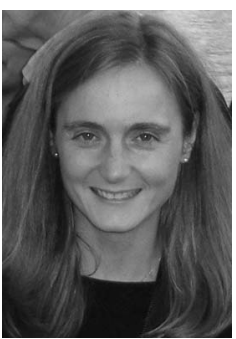
SAR Interferometry research group at the German Aerospace Center Microwaves and Radar Institute, Wessling, Germany. Her main research interests are in electromagnetic propagation and scattering theory, radar polarimetry, SAR and interferometric SAR data processing techniques, and environmental parameter modeling and estimation. From 1996 to 1999 , she was with the Microwaves and Radar Institute (DLR-HF), German Aerospace Center (DLR), Oberpfaffenhofen, Germany. From 1999 to 2000, she was with the Institut d'Electronique et de Télécommunications de Rennes, University of Rennes 1, France (for ten months) and with the Applied Electromagnetics (AEL), St. Andrews, Scotland (for four months), in the frame of the EC-TMR Radar Polarimetry Network. In 2005, she was a guest scientists at the University of Adelaide, South Australia (for six weeks). She is the science coordinator of the German satellite mission TanDEM-X.

Thomas Jagdhuber (Student Member, IEEE) was born in Munich, Germany, in 1979. He received the Diploma degree (with honors) in physical geography, physics, and remote sensing from Ludwig Maximilian University of Munich, Munich, Germany, in 2006 and the Ph.D. degree from the University of Potsdam, Potsdam, Germany, in 2012.

Currently, he is a Postdoctoral Fellow at the Microwaves and Radar Institute, German Aerospace Center, Wessling, Germany. His main re-

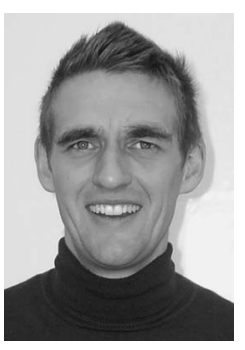
search interests include microwave remote sensing with an emphasis on polarimetric and polarimetric interferometric techniques for hydrological, agricultural, and snow parameter modeling and estimation. Therefore, he is also involved in the analysis of several high-resolution F-SAR campaigns for geophysical parameter estimation.

Dr. Jagdhuber serves as a reviewer for several international journals.

Konstantinos P. Papathanassiou (Senior Member, IEEE) received the Dipl. Ing degree (honors) and the Dr. degree (honors) from the Technical University of Graz, Graz, Austria, in 1994 and 1999, respectively.

From 1992 to 1994, he was with the Institute for Digital Image Processing (DIBAG) of Joanneum Research, Graz, Austria. Between 1995 and 1999, he worked at the Microwaves and Radar Institute (HR) of the German Aerospace Center (DLR), Wes-

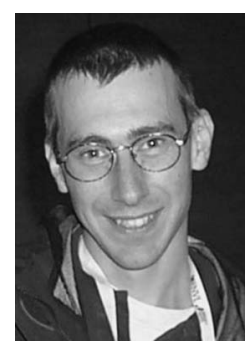
sling, Germany. From 1999 to 2000, he was a European Union (EU) Postdoctoral Fellow with Applied Electromagnetics (AEL), St. Andrews, Scotland. Since October 2000, he has been again with the Microwaves and Radar Institute (HR) of the German Aerospace Center (DLR). Currently, he is a Senior Scientist leading the Information Retrieval research group at DLR-HR. His main research interests are in polarimetric and interferometric processing and calibration techniques, polarimetric SAR interferometry, and the quantitative parameter estimation from SAR data, as well as in SAR mission design and SAR mission performance analysis. He has more than 100 publications in international journals, conferences, and workshops.

Dr. Papathanassiou was awarded the IEEE Geoscience and Remote Sensing Society (GRSS) International Geoscience and Remote Sensing Symposium (IGARSS) Prize Paper Award in 1998, the Best Paper Award of the European SAR Conference (EUSAR) in 2002, and the DLR science award in 2002. In 2011, he was awarded with DLR's Senior Scientist Award.
Matteo Nannini received the Laurea degree in telecommunication engineering from the University of Florence, Florence, Italy, in 2003, with a thesis done in collaboration with the Microwaves and Radar Institute (HR) of the German Aerospace Center (DLR), Wessling, Germany and the Ph.D. degree from the University of Karlsruhe, Karlsruhe, Germany, in 2009, with a thesis on synthetic aperture radar tomography.

Since 2004, he has been with the Microwaves

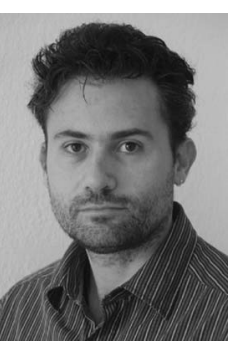
and Radar Institute of DLR. His main research activities are synthetic aperture radar processing, differential interferometry, tomography, and radar sounding.

Dr. Nannini was awarded, as co-author, the best paper prize at the joint SEAS \& EMRS DTC Technical Conference in Edinburgh, U.K., in 2009 and 2010, respectively.

Esteban Aguilera was born in Mendoza, Argentina, on September 11, 1983. He received the Ingeniero degree in information systems engineering from the National Technological University, Mendoza, Argentina, in 2007. Currently, he is working toward the Ph.D. degree at the Microwaves and Radar Institute, German Aerospace Center (DLR), Wessling, Germany.

From 2008 to 2009, he worked as a Consultant to a wide range of information technology (IT)

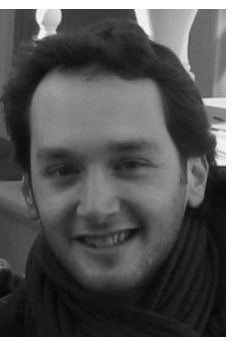
projects in Belgium and The Netherlands. His main research interests are in polarimetric synthetic aperture radar (SAR), SAR interferometry, and SAR tomography.

Stefan Baumgartner (Student Member, IEEE) received the Dipl.-Ing. degree in electrical engineering and communication technology from the Graz University of Technology, Graz, Austria, in 2004.

Since 2004, he has been with the Microwaves and Radar Institute (HR), German Aerospace Center (DLR), Wessling, Germany. He is currently with the Radar Concepts Department, where his field of activity is the development of ground moving target indication and parameter estima-

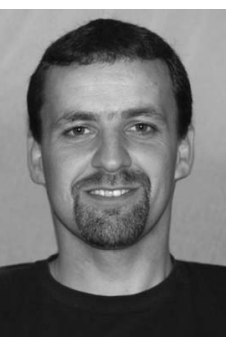
tion algorithms for future road-traffic-monitoring applications using multichannel airborne and spaceborne synthetic aperture radars (SARS). His research interests include SAR along-track interferometry, spacetime adaptive processing (STAP), time-frequency analysis, and other advanced signal and imaging processing techniques.

Ralf Horn received the Dipl.-Ing. degree in electrical engineering, with major subjects in telecommunications and radio-frequency engineering, from Ruhr Universitaet Bochum, Bochum, Germany, in 1983.

Since 1983, he has been with the SAR Technology Department, Microwaves and Radar Institute, German Aerospace Center (DLR), Wessling, Germany, where from 1983 to 1986 , he was first a Radar Engineer for the development of DLR's

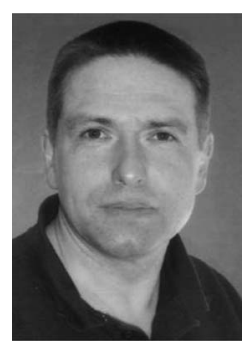
airborne Experimental SAR system E-SAR and was later a SAR Systems Engineer. Then, in 1994, he was promoted to Team Leader of the "Airborne SAR" group of the SAR Technology Department. His current responsibilities are focused on the project management for the new DLR airborne SAR system F-SAR and on the management, coordination, and execution of the DLR airborne SAR missions in Europe and abroad. 
This article has been accepted for inclusion in a future issue of this journal. Content is final as presented, with the exception of pagination.

Reigber et al.: Very-High-Resolution Airborne Synthetic Aperture Radar Imaging

Anton Nottensteiner received the Dipl.-Ing. degree in electrical engineering, with focus on microwave technology, from the Technische Universität München, Munich, Germany, in 1980.

He has held a leading position in the microwave system development, especially for satellite communications. Since 1997, he has been with the SAR Technology Department, Microwaves and Radar Institute, German Aerospace Center (DLR), Wessling, Germany. In 1998, he was promoted to Team Leader of the "Radar Electronic" group of the SAR Technology Department. He is responsible for aircraft radar hardware development.

Alberto Moreira (Fellow, IEEE) was born in São José dos Campos, Brazil, in 1962. He received the B.S.E.E. and M.S.E.E. degrees from the Aeronautical Technological Institute (ITA), São José dos Campos, Brasil, in 1984 and 1986, respectively, and the Eng. Dr. degree (with honors) from the Technical University of Munich, Munich, Germany, in 1993.

From 1996 to 2001, he was the Chief Scientist and Engineer with the SAR Technology Department, German Aerospace Center (DLR), Wessling, Germany. Under his leadership, the DLR airborne SAR system has been upgraded to operate in innovative imaging modes like polarimetric SAR interferometry and SAR tomography. Since 2001, he has been the Director of the Microwaves and Radar Institute at DLR. The Institute contributes to several scientific programs and space projects for actual and future airborne and spaceborne SAR missions like TerraSAR-X, TanDEM-X, SAR-Lupe, Sentinel-1, and Tandem-L. The mission TanDEM-X, led by his Institute, has successfully started the operational phase in December 2010. He is the initiator and Principal Investigator for this mission. Since 2003, he has been a Full Professor with the Karlsruhe Institute of Technology, Karlsruhe, Germany, in the field of microwave remote sensing. He has more than 300 publications in international conferences and journals and is the holder of 15 patents in the radar and antenna field. His professional interests and research areas encompass radar end-to-end system design and analysis, innovative microwave techniques and system concepts, signal processing, and remote sensing applications.

Prof. Moreira is a member of the IEEE Geoscience and Remote Sensing Society (GRSS) Administrative Committee (1999-2001, 2004-2013, 2010 as President, 2011-2013 as Past-President), was the Founder and Chair of the GRSS German Chapter (2003-2008) and Associate Editor for the IEEE Geoscience and Remote Sensing Letters (2003-2007) and for the IEEE Transactions on Geoscience and Remote Sensing (2005-2011). He and his colleagues received the GRSS Transactions Prize Paper Awards in 1997, 2001, and 2007 and the IEEE W.R.G. Baker Award in 2012. He is also the recipient of the DLR Science Award (1995), the IEEE Nathanson Award for the Young Radar Engineer of the Year (1999), and the IEEE Kiyo Tomiyasu Field Award (2007). He served as a member of the Board of Directors of the Information Technology Society of the German Association for Electrical, Electronic and Information Technologies (2003-2008) and as Chair of the Scientific and Technical Council of DLR (2009-2011). He has contributed to the successful series of the European SAR conferences (EUSAR) since 1996 as a member of the Technical Program Committee, Technical Chairman (2000), Awards Chairman (2002-2004), General Chairman (2006), and Co-Chairman (2008), and has served as General CoChair for the 2012 International Geoscience and Remote Sensing Symposium, Munich, Germany. 